\title{
New excavations at the HWK EE site: archaeology, palaeoenvironment and site formation processes during late Oldowan times at Olduvai Gorge, Tanzania
}

Ignacio de la Torre $^{1 *}$, Rosa M. Albert ${ }^{2,3}$, Adrián Arroyo ${ }^{1}$, Richard Macphail ${ }^{1}$, Lindsay J. McHenry ${ }^{4}$, Rafael Mora ${ }^{5}$, Jackson K. Njau ${ }^{6,7}$, Michael C. Pante ${ }^{8}$, Carlos A. Rivera-Rondón ${ }^{9}$, Ágata Rodríguez-Cintas ${ }^{3}$, Ian G. Stanistreet ${ }^{10,7}$, Harald Stollhofen ${ }^{11}$ and Karol Wehr ${ }^{1}$

${ }^{1}$ Institute of Archaeology, University College London, 31-34 Gordon Square, WC1H OPY London, United Kingdom

${ }^{2}$ ICREA, Pg. Lluís Companys 23, 08010 Barcelona, Spain

${ }^{3}$ ERAAUB/Departament de Historia i Arqueologia, Universitat de Barcelona. Montalegre 6-8, 08001 Barcelona, Spain

${ }^{4}$ Department of Geosciences, University of Wisconsin- Milwaukee, 3209 N. Maryland Ave., Milwaukee, WI 53211 USA

${ }^{5}$ Centre d'Estudis del Patrimoni Arqueologic de la Prehistoria, Facultat de Lletres, Universitat Autonoma de Barcelona, 08193 Bellaterra, Spain

6 Department of Geological Sciences, Indiana University, 1001 East 10th Street, Bloomington, IN 47405-1405, USA

${ }^{7}$ Stone Age Institute, 1392 W Dittemore Road, Gosport, Indiana 47433, USA.

8 Department of Anthropology, Colorado State University, 1787 Campus Delivery, Fort Collins, CO 80523 USA

9 Unidad de Ecología y Sistemática, Departamento de Biología, Pontificia Universidad Javeriana, Cra. 7 \# 40-82, 110231 Bogotá, Colombia

${ }^{10}$ Department of Earth, Ocean and Ecological Sciences, University of Liverpool, Brownlow Street, Liverpool L69 3GP, United Kingdom

11 GeoZentrum Nordbayern, Friedrich-Alexander-University (FAU) Erlangen-Nürnberg, Schloßgarten 5, 91054 Erlangen, Germany

* Corresponding author: i.torre@ucl.ac.uk 


\begin{abstract}
This paper reports the results of renewed fieldwork at the HWK EE site (Olduvai Gorge, Tanzania). HWK EE is positioned across the boundary between Lower and Middle Bed II, a crucial interval for studying the emergence of the Acheulean at Olduvai Gorge. Our excavations at HWK EE have produced one of the largest collections of fossils and artefacts from any Oldowan site, distributed across several archaeological units and a large excavation surface in four separate trenches that can be stratigraphically correlated. Here we present the main stratigraphic and archaeological units and discuss site formation processes. Results show a great density of fossils and stone tools vertically through two stratigraphic intervals (Lemuta and Lower Augitic Sandstone) and laterally across an area of around $300 \mathrm{~m}^{2}$, and highlight the confluence of biotic and abiotic agents in the formation of the assemblage. The large size and diversity of the assemblage, as well as its good preservation, qualify HWK EE as a reference site for the study of the late Oldowan at Olduvai Gorge and elsewhere in Africa. In addition, the description of the stratigraphic and archaeological sequence of HWK EE presented in this paper constitutes the foundation for further studies on hominin behaviour and palaeoecology in Lower and Middle Bed II.
\end{abstract}

Keywords: Early Stone Age; Early Pleistocene; Taphonomy; Spatial analysis; Palaeoecology; Oldowan-Acheulean transition

\title{
Introduction
}

Olduvai Gorge (Tanzania) is one of the world's most important palaeoanthropological areas for the study of the Oldowan to Acheulean transition, due to the presence of archaeological sites in a relatively continuous stratigraphic sequence where a predominance of core and flake assemblages is replaced by handaxe-bearing sites (Leakey, 1951). Thanks to pioneering work by Mary Leakey (1971), the tempo of such technological change was narrowed down to Middle Bed II. In this stratigraphic interval, Leakey (1971) excavated a number of assemblages -now classic in the literature- where she observed a technological evolution within the Oldowan (which she attributed to Homo habilis), and an eventual replacement by the Acheulean (which she linked to Homo erectus). One of those sites was HWK EE, the subject of this paper.

The outcrop of HWK EE (Henrietta Wilfrida Korongo East East) is located in the southeast part of the Junction Area at Olduvai Gorge (see Fig. 1) and a few hundred meters from HWK $E$, one of the sites published in Leakey's (1971) classic monograph. Middle Bed II deposits were excavated at HWK EE by Mary Leakey in the early 1970s, but she never published her work at the site. HWK EE remains poorly known, and referenced almost exclusively for its stratigraphic sequence (Hay, 1976), the discovery of a tooth of cf. $H$. habilis, and the evolution of Olduvai bovids (Gentry and Gentry, 1978). As a result, the site has been rarely 
included in any discussions about Beds I and II of the Olduvai sequence from the 1980s until the present.

The large size and good preservation of the HWK EE Leakey collection, along with its stratigraphic position in the basal part of Middle Bed II (which is essential for the discussion of the Oldowan-Acheulean transition) at $\sim 1.7$ million years ago, indicated the potential of the site to provide information about hominin behaviour and technology during this crucial period of human evolution. In 2008, the Olduvai Geochronology Archaeology Project (OGAP) began a re-study of the unpublished Leakey assemblage (see Pante and de la Torre, submitted), and in 2009 renewed excavations at the site.

Excavations at HWK EE between 2009 and 2015 became one of the major fieldwork undertakings by OGAP and, as a result, a substantially large (one of the largest at Olduvai and elsewhere in Africa) bone and lithic assemblage has been recovered. Abundance, diversity and overall importance of the HWK EE archaeological record allows detailed studies of the zooarchaeology (Pante et al., submitted), lithic technology (de la Torre and Mora, submitted), and mammal isotopic and tooth wear patterns (Rivals et al., submitted). The HWK EE record also constitutes the main dataset for several other studies on the Olduvai battered tools (Arroyo and de la Torre, submitted), raw materials (McHenry and de la Torre, submitted), and palaeoecology (Bibi et al., this volume; Uno et al., this volume; Prassack et al., this volume) of Bed II.

The present paper aims to introduce the archaeological sequence of HWK EE to provide the foundation for all the aforementioned studies. Based on a cross-disciplinary approach, this paper presents a full and extensive account of the archaeo-stratigraphic sequence, site formation processes and palaeoenvironment of HWK EE, drawing from detailed studies of tephrostratigraphy, sedimentology, micromorphology, diatoms, phytoliths, taphonomy and spatial analysis of the assemblage. While palaeoecological patterns and an interpretation of hominin behaviour/s involved in the formation of HWK EE will be discussed in accompanying papers, this paper will provide the necessary picture to contextualise hominin activities and their environment during late Oldowan times at Olduvai Gorge.

\section{Materials and methods}

\section{Archaeological excavation}

A virtual grid with a local coordinate system was created in the area of the HWK EE outcrop. Cemented reference stations were placed around the main excavation and satellite trenches. This relative coordinate grid was aligned with Mary Leakey's trench at HWK EE, so that the OGAP trench could be extended from Leakey's trench walls. Such alignment does not correspond to geographic North, and thus the northing ( $Y$-axis) of the HWK EE relative system is at $38^{\circ}$. The local coordinate system was used during excavations, and cemented reference stations were then geo-located with differential global navigation satellite system (GNSS). Finally, the local grid system was transformed into absolute coordinates. All plans and maps used the World Geodetic System 1984 (WGS84), which are mostly expressed 
throughout this paper in degrees, minutes, seconds. However, in some instances when a particular plan covers a smaller area, WGS84 datum in a Universal Transverse Mercator Zone 36 South (UTM36S) projection was used and expressed in meters.

Excavations focused on extending Leakey's trench to the east into what we named T1-Main Trench, and three satellite trenches spaced several meters from each other to the west of Leakey's trench. Excavation methods followed protocols outlined by de la Torre et al. (2015), based on 3D plotting with a total station of all fossils and lithics, as well as palaeoenvironmental samples and geological and topographic features that were observed during excavation. Dry sieving was conducted for all excavated sediments with $6 \mathrm{~mm}$ mesh sieves, and all materials (fossils, artefacts and lithic clasts) were collected and catalogued. All stone tools and natural lithic clasts recovered from sieving were given a unique ID and assigned random coordinates within the one $\mathrm{m}^{2}$ from which they derived. Relevant fossils recovered through sieving were also individualized in the same way, and the rest grouped in level bags with 3D coordinates per $\mathrm{m}^{2}$ and archaeological unit. All plotted specimens (including natural pebbles and cobbles) with a stratigraphic context were analysed fully for this paper.

Archaeological units were defined during fieldwork following lithological contacts and vertical clustering of material. Vertical clustering was the main (although not exclusive) criterion used to individualize archaeological units in T1-Main Trench, due to the difficulty of distinguishing lithological contexts during the excavation process. In the satellite trenches, where lithological contacts are more conspicuous, lithofacies and vertical clustering played equal parts in the separation of archaeological units. As a result, there are lithological layers that include more than one archaeological unit, and archaeological units that span more than one lithological layer. Fieldwork decisions on the individualization of archaeological units were then cross-checked with geostatistical methods (see below).

\section{Stratigraphy}

Stratigraphic sections were measured in the vicinity of HWK EE as far west as HWK W and to KK in the east, spanning $\sim 650 \mathrm{~m}$. All sections begin with Tuff IF, the top of which marks the base of Bed II, and selected sections (one each from HWK W, HWK E, and HWK EE) cover the entire thickness of Bed II up to the base of Bed III. All other sections cover at least the section between Tuffs IF and IIB, which includes the levels of interest for the HWK EE excavations. A rock hammer was used to clear exposures for section measuring, a meter stick was used to measure thicknesses within a section, and a Jacob's staff and level were used to sight from one section to the next and measure more expanded sections. Tuffs, and stratigraphic units within Bed II (e.g., Lemuta Member, and Lower Augitic Sandstone [LAS]) follow the nomenclature of Hay (1976), and are constrained within the tephro-stratigraphic framework presented in McHenry et al. (2016). On a regional scale, the HWK EE strata are correlated with time-stratigraphic equivalents by an integrated sequence stratigraphic and tephrostratigraphic approach (Stanistreet et al., submitted).

Bulk analysis and micromorphology 
Twenty-three bulk samples spanning most of the stratigraphic interval exposed at HWK EE were collected from the four excavated trenches, and processed for grain size analysis. This included standard methods such as the Robinson pipette, and classification of lithologies based on Folk (1959) and Sheppard (1954) diagrams.

Four blocks were collected from T1-Main Trench for micromorphology analysis. Following protocols by Goldberg and Macphail (2006) and Murphy (1986), geological samples were impregnated with a mixture of clear polyester resin-acetone, topped up with resin, and then cured and slabbed for manufacture of eight $75 \times 50 \mathrm{~mm}$-size thin sections. These thin sections were further polished with 1,000 grit papers and analysed using fluorescence microscopy (blue light $[\mathrm{BL}]$ ) and petrographic microscopy under crossed polarised light $(X P L)$, plane polarised light (PPL) and oblique incident light (OIL), at $1 x$ to $200 / 400 x$ magnifications. Two of the samples (\#26B and \#28A) were subjected to scanning electron microscopy / energy dispersive X-ray spectroscopy (SEM/EDS) analysis. Soil microfabric types (MFTs) and microfacies types (MFTs) were described following established protocols (e.g. Bullock et al., 1985; Courty et al., 1989; Courty, 2001; Macphail and Cruise, 2001; Stoops, 2003; Stoops et al., 2010).

\section{Diatoms}

Diatom valves were extracted following an oxidative procedure (Renberg, 1990). Thirty sediment samples (20-40 mg) were processed using $30 \% \mathrm{H}_{2} \mathrm{O}_{2}$ in a water bath at $65{ }^{\circ} \mathrm{C}$, over $96 \mathrm{~h}$. After digestion, the samples were washed with distilled water, and the diatom concentration was estimated adding a known volume of a latex microsphere solution. The valves were mounted on permanent slides using Naphrax. A minimum of 300 valves were counted using a Zeiss Axio-A1 microscope with interferential contrast. The identification and interpretation of the material was conducted using standard protocols (Krammer and Lange-Bertalot, 1991, 2004; Lange-Bertalot, 2001) and literature specific to the fossil material of the region (Gasse, 1980, 1986; Gasse and Tekaia, 1983; Caljon, 1991). Valve dissolution was estimated by counting the number of valves with evident dissolution. Fragmentation was estimated by counting the number of fragmented valves and using a fragmentation index adapted from the dissolution index of Ryves et al. (2009), but assigning each valve to a scale of fragmentation (1: intact valves; 2: valves with small breakage; 3 : valves with a unique large breakage; 4: valves with multiple damage). The index ranges from 0 to 1 , with 1 assigned when all valves show the highest fragmentation state.

\section{Phytoliths}

Thirty samples were processed for phytolith analysis following methods developed by Katz et al. (2010). Samples were treated with $50 \mathrm{ml}$ of hydrochloric acid solution (6N HCL) to dissolve carbonates and $450 \mathrm{ml}$ of $2.4 \mathrm{~g} / \mathrm{ml}$ sodium polytungstate solution $\left(\mathrm{Na}_{6}\left(\mathrm{H}_{2} \mathrm{~W}_{12} \mathrm{O}_{40}\right)\right.$ $\cdot \mathrm{H}_{2} \mathrm{O}$ ) to separate their components. Afterwards, samples were sonicated and centrifuged (MiniSpin plus, Eppendorf). An Olympus BX41 optical microscope was used for quantitative and morphological phytolith identification, at 200x and 400x magnification respectively. A minimum of 200 phytoliths were counted for the morphological analysis, but when this was 
not possible only samples with a minimum number of 50 phytoliths were interpreted (Albert and Weiner, 2001).

\section{Lithic and bone analysis}

A detailed taphonomic analysis of the HWK EE fauna was conducted following the methods and criteria prescribed by Blumenschine et al. (1996), and included inspection with the naked eye under a 60 -watt light source, followed by more detailed examination using a $10 \mathrm{x}$ hand lens and dino-lite portable microscope with up to 200x magnification. These methods are further detailed in Pante et al. (submitted). Taphonomic data collected and presented here include bone weathering based on Behrensmeyer's (1978) criteria and a general account of the condition of cortical surfaces as measured by exfoliation, rounding, and relative coverage by adhering matrix. More detailed taphonomic analysis focusing on the feeding ecology of hominins can be found in Pante et al. (submitted). Taxonomic and palaeoecological aspects of HWK EE are further discussed by Bibi et al. (submitted) and Rivals et al. (submitted).

All HWK EE lithics (both natural and artefacts) were measured irrespective of their size, and their raw material classified according to McHenry and de la Torre's (submitted) identifications. Two variables of edge damage (rounding and microfracturing) were recorded in stone tools, following standard terminology (Levi Sala, 1986; Shea, 1999; see further discussion in de la Torre and Wehr, submitted). General stone tool categories distinguished between detached, flaked and battered artefacts, as defined by Isaac et al. (1997). Detailed accounts are presented elsewhere on the battered (Arroyo and de la Torre, submitted) and flaked and detached pieces (de la Torre and Mora, submitted) excavated by OGAP, as well as those excavated by Leakey (Pante and de la Torre, submitted). Statistical comparisons included the Pearson's chi-squared test (Pearson, 1900) and correspondence factor analysis (e.g., Teil, 1975).

Refit analysis was conducted on fossils and stone tools. All material above $20 \mathrm{~mm}$ was considered for conjoin analysis, and refitting attempts included materials from all archaeological units and trenches. To account for the well-known decreasing return in refit success, we decided to invest a total of 98 hours in the refit analysis of the fossil assemblage, and 95 hours in the conjoining of stone tools. Distance, orientation and slope of refit lines were calculated with an ArqueoUAB (Mora et al., 2010) algorithm.

\section{Spatial analysis}

Density analysis focused on T1-Main Trench due to the larger size of the excavation surface, and compared the distributions of the three main types of objects (fossils, stone tools and unmodified lithics) across the trench, and of some of their main attributes (e.g. raw material type, fossil weathering and size ranges). The process followed a standard algorithm, placing a probability density function with optimum bandwidth across observed points (Conolly and Lake, 2006), resulting in intensity maps with values in number of artefacts per $\mathrm{mm}^{2}$.

Density analysis was also applied to $\mathrm{XZ}$ and $\mathrm{YZ}$ axes along with cluster analysis with multiple statistical tests (MacQueen, 1967; Ripley, 1976, 1981; Kaufman and Rousseeuw, 1990), to 
support archaeological unit identification. Density estimation for the entire site (i.e. areas surrounding trenches) followed the same principle, but was applied to a randomly distributed number of points calculated using the lower estimate of density across the site.

Point pattern analysis was based on kernel density maps and geostatistical methods, such as the Clark and Evans nearest neighbour test (Clark and Evans, 1954) and Ripley's K-function (Ripley, 1976). Ripley's K-function tested the distribution against a Poisson line of total spatial randomness along with a buffer of 99 simulation runs, where the clustering/randomness is tested at multiple scales (Robert and Casella, 2004).

Predictive models and relative probability surfaces (Haining, 2003) were produced, applying a multivariate logistic regression using geostatistic morphometric variables (elevation, slope, aspect, curvature and erosion level). Each variable was tested for its predictive power separately and in relation to other variables using Akaike Information Criteria (Akaike, 1973, 1974), both as a whole and divided into sub-groups. Resulting models are combinations of best-fitting variables. The models were subsequently validated (Kvamme, 1983, 1988).

Orientation patterns and analysis of artefact fabrics

Analysis of orientations and fabrics of artefacts and fossils was performed in two iterations of each dataset (the first including all items with orientation data, and the second including only objects with length $>20 \mathrm{~mm}$ and elongation index $>1.6$ ). Circular histograms were produced using the R package circular (Ihaka and Gentleman, 1996; Lund and Agostinelli, 2007) with lower closed bins, and orientation patterns were tested with Rayleigh's and Kuiper's tests of uniformity (Bertran and Lenoble, 2002; Benito-Calvo and de la Torre, 2011). Fabric analysis included only datasets with an elongation index (le) $>1.6$. Analysis of fabrics included generation of Benn's diagrams (Benn, 1994) using a modified version of Tri-plot (Graham and Midgley, 2000) and calculation of multiple fabric statistics, eigenvectors and eigenvalues (Curray, 1956; Sneed and Folk, 1958; Woodcock, 1977; Bertran and Lenoble, 2002; Benito-Calvo et al., 2009).

Several other statistical tests were applied to spatial and orientation data. These included Jenks' optimal method (Jenks, 1971), Kolmogorov-Smirnov test (Daniel, 1990), Pearson's chisquared test (Pearson, 1900), Shapiro-Wilk test (Shapiro and Wilk, 1965), analysis of variance (Fisher, 1925), Tukey's post hoc HSD (Tukey, 1949) and Student's t-test (Student, 1908).

\section{The stratigraphic position of HWK EE}

The stratigraphic position of the HWK EE site is constrained between Tuffs IIA (1.72 +/- 0.03 Ma: see discussion in Stanistreet 2012) and IIB (Fig. 2). Leakey (1971) placed the base of Middle Bed II at the top of Tuff IIA. However, Hay (1976) superseded this by defining a formal stratigraphic unit, the Lemuta Member, which straddled Tuff IIA. Hay (1976) correlated Tuff IIA laterally as the middle tongue of three "eolian tuffs", technically sandstones, that spread westwards into the Junction area from the direction of the eastern Main Gorge. We seek to reintroduce Leakey's (1971) term "Middle Bed II," but Hay's 
definition of the Lemuta Member requires us to redefine the base of Middle Bed II as the unconformity that underlies the LAS. Further discussion of this revision can be found in Stanistreet et al. (submitted).

In the vicinity of HWK EE, lacustrine claystones mark the top of lowermost Bed II and are capped either by the Lemuta Member (including Tuff IIA and/or other Lemuta sandstones and claystones) or by the LAS, which fills incised surfaces into the Lemuta and further down into lowermost Bed II in places (Fig. 2). To the east of HWK EE, the Tuff IIB interval overlies the LAS, though this is not preserved to the west of the site and constitutes only a thin unit in the upper backwall of the main trench at HWK EE. To the east of HWK EE, the marker bed Bird Print Tuff (BPT: see McHenry et al. (2016) for diagnostic characteristics) is found slightly above the level of Tuff IIB, though this interval is conspicuously absent at HWK EE and at nearby sites to the east. The materials excavated in the four trenches in the HWK EE area are stratigraphically constrained between Tuff IIA and Tuff IIB.

\section{The OGAP trenches at HWK EE}

Four trenches were dug at HWK EE by OGAP (Fig. 3 and Supplementary Online Material [SOM] S1). Excavations started in 2009 by extending the east limit of Mary Leakey's original trench into the outcrop. This trench, termed T1-Main Trench, was excavated during seven more field seasons between 2010 and 2015. OGAP's T1-Main Trench at HWK EE extended $\sim 32 \mathrm{~m}^{2}$ to the east and northeast of Leakey's trench, sampled a stratigraphic interval of $\sim 5.1$ $\mathrm{m}$ from the top of the excavated deposits to the base of the trench, and unearthed an approximate volume of $\sim 49 \mathrm{~m}^{3}$ of sediments.

To retrieve data from the same stratigraphic interval across the HWK EE exposures, three satellite trenches were excavated in the western part of the outcrop: T27 and T28 were both excavated during two field seasons in 2014, each exposing an area of $2 \times 1 \mathrm{~m}$, and sampling deposits of $2.7 \mathrm{~m}$ (T27) and $2.6 \mathrm{~m}$ (T28) in thickness. T27 is $2.5 \mathrm{~m}$ west of Leakey's HWK EE trench and $6 \mathrm{~m}$ west of T1-Main Trench, while T28 was placed at $6 \mathrm{~m}$ to the west of T27 (see details in Table 1). T29 was excavated during a single field season in 2014. At $10 \mathrm{~m}$ from T28, T29 is the westernmost trench dug at HWK EE, covering an area of $3 \mathrm{~m}^{2}$, and exposing a maximum thickness of $2.2 \mathrm{~m}$.

Trenches were deemed to be complete when a unit of green waxy claystone that occurs within Lower Bed II was reached. This lacustrine claystone was exposed across the entire trench in T27 and T28, and sampled in a test pit at T1-Main Trench. Considering the four trenches together, OGAP sampled $39 \mathrm{~m}^{2}$ at HWK EE, across an area of $288 \mathrm{~m}^{2}$ from the west of T29 to the east of T1-Main Trench, excavating approximately $55 \mathrm{~m}^{3}$ of Lower Pleistocene deposits throughout a thickness of $5.6 \mathrm{~m}$ from the top (T1: elevation $1411.6 \mathrm{~m}$ above sea level [a.s.I.]) to the lowermost part (T28: elevation $1406 \mathrm{~m}$ a.s.I.) of the sampled deposits.

\section{Stratigraphic and sedimentological features of HWK EE trenches}


Excavations at HWK EE sampled four main stratigraphic intervals, from lowermost Bed II (LBII) at the bottom (represented by green waxy claystones) and the Lemuta Member comprising Tuff IIA, overlain by Lemuta claystone. The LAS and the Tuff IIB zone (sandstones and diamictites with thin claystone interbeds) represent Middle Bed II at the top of the sequence.

Tuff IIA, a marker bed of varying pyroclastic content defined in Hay (1976), is a multi-layered unit comprising moderately augitic, fine to medium tuffaceous sandstone and clayey coarse sandstone. In Trenches T28 and T27, it sits between Lemuta waxy claystones (Fig. 4), while in Trench T29 excavation just penetrated through the Tuff IIA Lemuta sandstone. Above the Lemuta sequence in these trenches, the LAS sits on an incision surface that cuts down into the top of the higher claystone of the Lemuta Member, but in T1-Main Trench the surface cuts down into the top of Tuff IIA.

Bulk sample analysis (Fig. 5 and Table 2) further refines the field mapping of trench backwalls. For instance, a clear contrast is observed in the silt and clay component between the Lemuta and the LAS sandstones, with the latter containing consistently higher percentages of silts and clays. Likewise, the lower part of the Lemuta claystones is compositionally homogeneous in T27 and T28 but contains more sand-sized detrital material in T1, while the higher Lemuta claystone (which is sandier than the LBII clay throughout) has higher silt and clay content in T29 and T28 than in T27 (see Table 2).

\section{The archaeological sequence of T1-Main Trench}

T1-Main Trench (Fig. 6 and SOM S2) produced the largest number of archaeological remains (14,987 stone tools and 5,026 plotted bones, plus over 26,000 smaller bone fragments) at the HWK EE outcrop. Twelve archaeological units were identified during excavation (see Table 3). Although the definition of such units was often based on sterile gaps between vertically-distinctive clusters of remains (due to difficulties in identifying different lithologies during excavation), there is a good correspondence overall between sedimentological layers and archaeological units. Still, the gaps observed between vertical clusters (e.g., Fig. 6b) are not continuous across the trench and, in several areas -particularly in the southeast (Fig. 6d)-, some archaeological units are vertically indistinguishable, resulting in a complex archaeo-stratigraphic architecture (Figs. 6a-d).

We conducted statistical tests on the spatial arrangement of archaeological remains in order to examine the validity of field decisions on the definition of T1-Main Trench archaeological units. Such tests were applied to only the lower archaeological units (L1 down to L10), since the upper levels (L1E-L1C) are well separated from the underlying sequence, and therefore their individualization does not require further spatial analysis. K-means analysis proposed four clusters of archaeological remains, which are nonetheless biased towards the spatial attraction within the horizontal $(X, Y)$ distribution of remains. The PAM (partitioning around medoids) method enabled the introduction of additional variables into the matrix, although clustering is still biased towards vertical proximity of artefacts in the southern part of the trench, both when all the assemblage is considered (Fig. 7a), and when the material is 
analysed in selected sections (Fig. 7b). In addition, vertical values (Z) of all data were classified with Jenks' natural breaks method into five clusters. Clustering of remains according to Jenks' natural breaks results (Fig. 7c) is substantially similar to the archaeological units defined during fieldwork (Fig. 7d). Therefore, even though geostatistical tests cannot confirm the validity of level assignations, they provide additional support based on the spatial proximity and similarity of the distribution of the remains.

In summary, geostatistics support the existence of different archaeological units separated by vertical gaps, which point to the presence of several temporal events in the formation of the T1-Main Trench assemblage. Although such events are clearly jumbled in parts of the trench, our field-based archaeo-stratigraphy is nonetheless valid and enables us to differentiate several successive depositional episodes.

\section{Lemuta units}

The archaeological sequence of T1-Main Trench starts with L12, sampled in $2 \mathrm{~m}^{2}$ (Table 4) at the bottom of the Lemuta sandstones (Table 5) within the test pit targeting the LBII waxy claystones in the southeast corner of the trench (Fig. 6e). A $23 \mathrm{~cm}$ gap exists between L12 and the overlying unit, L10. Excavated across the entire trench area (Fig. 8a), L10 is contained within the top of the Lemuta sandstones and the overlying clayey sandstone (Table 5). With an average thickness of $\sim 52 \mathrm{~cm}$, L10 is one of the largest (Table 3) and densest (Table 4) assemblages excavated in T1-Main Trench (see also SOM S3 and SOM S4). The lower part of this unit contains some of the best-preserved fossil specimens in the HWK EE complex (Fig. 9a and Fig. 9b).

\section{LAS units}

L8 The lowermost archaeological unit in the LAS sequence is L8. This unit was identified only in the south end of T1-Main Trench (SOM S5), and sits directly over the finest (i.e. more clayey) part of the clayey sandstone layer. Although some specimens are embedded into the silty claystone, most were covered by sandstones. Therefore, we interpret the unit to have been deposited during the LAS interval, although it cannot be excluded that remains originally belonged to a Lemuta Member episode that was then exposed by LAS erosion.

L6-LCHA The grey coarse sandstone eroding through the clayey sandstone contains conglomerate lenses and cobbles arranged in clusters (Fig. 10a). Archaeological material in the northern part of the trench was named L6 and that in the south termed LCHA, but as the excavation progressed, it was observed that they both formed one single unit (Fig. 10b-e). Although in cross section L6-LCHA is vertically indistinguishable from L8, the sedimentary context and archaeological features are fairly distinctive; while $\mathrm{L} 8$ sits on claystone and is dominated by bones, in L6-LCHA large lithics dominate and bones are scarcer (see Table 3). In some parts of the trench, the LAS grey coarse sandstone also cuts down into the Lemuta sandstones underlying the clayey sandstone, further complicating the separation between L6-LCHA and L10 in some areas.

Micromorphology of sediments embedding L6-LCHA (sample \#26 in Fig. 5a) sheds more light on the formation of this archaeological unit. The upper part of the level (\#26B) is broadly 
layered, with a lower layer of claystone that contains fine sand, and a heterogeneous darker upper layer of poorly sorted fine to coarse sand-size material with gravel-size clay clasts, with burrow mixing of the upper layer into the lower layer. There are occasional fine leached bones, including probable fish bones (Fig. 11a), and occasional broad and many very broad burrows, becoming very abundant in the upper part. The upper part of L6-LCHA is slightly less minerogenic (1.65\% LOI) and phosphate-enriched ( $3.09 \mathrm{mg} \mathrm{g}-1$ ) than any other sampled units in T1-Main Trench (see Table 6). It is possible that coarser sedimentation truncated the lower layer, which is more biologically worked. Using EDS, a very strong leaching of apatite and only patchy apatite preservation was found, although small areas of better preserved bone also included fluorine (F), and embedded sediment included phosphorous (P).

Subsample \#26A (Fig. 11b) corresponds to the lower part of L6-LCHA, and includes heterogeneous, weakly massive, poorly sorted fine sands and gravels, with frequent gravelsize subrounded clay clasts. There are many small bone fragments, including fish. Bones are strongly leached, poorly birefringent and poorly autofluorescent. This lower part of L6-LCHA is characterised by rare examples of whitish clay void coatings and infills and associated matrix intercalations, occasional fine sand-infilled fissures/channels, and many broad and very abundant, very broad burrows (see Table 6). Overall, \#26A micromorphology documents moderate energy sands and gravels, testifying to erosion of underlying clayey beds, with high concentrations of small leached bones.

L4 The archaeological unit L4 is contained within the same grey coarse sandstone as L6LCHA. In the north of the trench there is a relatively thick $(\sim 16 \mathrm{~cm})$ sterile gap between L6 and the overlying $L 4$, which are separated by a cemented carbonate concretion. Towards the south, however, LCHA materials are higher up and thus L4 onlaps onto LCHA (see Figs. $12 \mathrm{~b}$-e). Due to this onlapping, some inter-assemblage admixture between L4 and L6-LCHA is almost certain. Table 4 shows that the average thickness of $L 4$ is $\sim 25 \mathrm{~cm}$, yielding a density of $\sim 57$ fossils/ $\mathrm{m}^{2}$ and $\sim 92$ stone tools/ $\mathrm{m}^{2}$. L4 contains the highest number of fossils after L10, including some of the most complete specimens (Figs. 9c-e), and also comprises a substantial lithic assemblage (Table 3).

Micromorphology thin sections (sample \#27 in Fig. 5a) reveal heterogeneous sediments at the top of L4 (subsample \#27A), with very broad burrows (Fig. 11e) filled with dark poorly sorted sands and clay clasts. Also present are fragments of weathered tuff within a bed of sands and gravel-size clay clasts (maximum $6 \mathrm{~mm}$ ), and rarely bones. Very abundant partially collapsed channels and vughs in burrows (forming polyconcave vughs) are also documented. The upper part of $L 4$ is thus characterised by massive sedimentary sands with later burrowing and effects of flooding causing structural collapse. Bone and fish bone have been leached, and phosphate measurements (see Table 6) may be recording both bone and phosphate-enriched fine sediment.

The lower part of the L4 thin section (\#27B) also contains heterogeneous sediments of weakly bedded, poorly sorted sands and clay clasts. These include $15 \mathrm{~mm}$-thick layers of gravel size material and $5 \mathrm{~mm}$-thick fine to coarse sand layers with burrow fill of dark sands and clay clasts. There are frequent fine to coarse gravels (clay and lava clasts), and many 
mammal and fish bone remains, some retaining traces of apatite mineralogy (ropy birefringence and $\mathrm{BL}$ autofluorescence). Occasional, partially collapsed channels and vughs in very abundant, very broad burrows, forming polyconcave vughs, occur. Despite strong leaching, the sediment is phosphate enriched (see Table 6), and probably also records phosphate stained fine sediment around bone fragments.

L2 The archaeological unit L2 is mostly embedded within a black medium sandstone overlying the grey coarse sandstone containing L4 and L6-LCHA. L2 is well constrained vertically (average of $21 \mathrm{~cm}$ thick), and a sterile gap between this unit and the underlying L4 is present across most of the trench (see Fig. 6). However, in the southern part of the excavation, the raised position of LCHA complicates unit differentiation based on elevation values. L2 archaeological remains were found across the entire excavation surface (at a density of 29 fossils/ $\mathrm{m}^{2}$ and $\sim 80$ stone tools/ $\mathrm{m}^{2}$, see further details in Table 4), but were rarer in the southern end of the trench (Fig. 13).

Thin sections of L2 (sample \#28 in Fig. 5a) show that the top of the unit (\#28A) is made up of heterogeneous fine to coarse sands and fine gravels composed of clay clasts (Fig. 14a), with very broad dark burrow fills and possible occasional brown clay void infillings of channels (Fig. 14b). There are occasional fish bones and porous bone with ropy birefringence, and some examples showing possible coprolitic staining. Analysis via SEM/EDS of various clay clasts and bone fragments found that bone was totally leached in places, but with a residual Ca-P apatite chemistry elsewhere that is still autofluorescent under BL (Fig. 14c). The lack of iron staining and presence of only residual bone is consistent with long periods of water saturation, and consequent hydromorphic leaching. Clay clasts were shown to be aggregates of different weathered clayey clast materials (Fig. 14d), presumably eroded from poorly sorted mass-flow deposits (cf. diamictite).

The lower part of archaeological unit L2 (\#28B) is composed of moderately heterogeneous, massive, very poorly sorted sands and gravels, which are very abundantly burrowed with very dark (potentially once humic) fills (Fig. 14e). Sediment is poorly sorted with common fine gravel size clay clasts (maximum $6 \mathrm{~mm}$ ), and with well sorted silt and fine sandy excrements. There is a rare instance of blackened/Fe-Mn-replaced root (Figs. $14 \mathrm{f}$ and $\mathrm{g}$ ), and rare (becoming occasional) weathered mammal/fish bone down-profile. Occasional ironmanganese replacement of organic materials (roots and amorphous organic matter) is observed, with abundant thin, broad and very broad burrows (and associated root channels), occasional partial fissure/channel fills of aggregated thin organic-mineral excrements, and phosphate enrichment (see values in Table 6).

L1-L1A The top of LAS contains abundant archaeological material in black and grey medium sandstones (Fig. 6d), which are vertically separated from L2 by a $\sim 10 \mathrm{~cm}$ gap. This gap is moderately continuous throughout the trench (but see geometry of materials in Fig. 6c), and therefore qualified separation between the archaeological unit of $L 2$ and the overlying cluster of remains, named L1. L1A refers to some materials on top of the main vertical concentration of L1, but given its scarcity (see Table 3 ) and vertical proximity to L1, remains from L1A (the uppermost ones in the LAS Member) are considered here alongside L1. With over 5,400 artefacts, L1-L1A has the largest lithic assemblage unearthed in HWK EE (see 
Table 3), but contained much less fossil material, despite the large surface excavated (Fig. 15a). L1 is a much thicker unit than other underlying archaeological levels and, while in some parts of the trench it could be interpreted as a single vertically homogeneous cluster, cross-sections of selected areas (e.g. Fig. 15d-e) show that the unit is composed of several overlapping depositional events.

The upper part of L1 (subsample \#29A) is broadly layered and massive (Fig. 16a), with thin (4-6 mm) layers of sparite-cemented clay soil clasts ( 0-5 mm and 30-40 mm depth), and clay laminae (Fig. 16b and Fig. 16c). There are also fine sandy and fine to medium sandy layers with frequent fine to medium (maximum $6 \mathrm{~mm}$ ) gravel-size clay clasts, which are also richer in magnetite and volcanic debris.

In contrast to the layering of the upper part of L1, lower sediments (\#29B) of this archaeological unit are massive, patchily calcitic and composed of moderately heterogeneous, very poorly to moderately sorted fine sandy and fine to medium sands and gravels. Also present are very abundant burrowed dark sands and gravels and very few burrows with very dark (Fe-Mn) fills (Fig. 16d). There are rare fine leached bone fragments (maximum $1.7 \mathrm{~mm}$ ), and an example of a $2.5 \mathrm{~mm}$ wide root residue (Figs. 16e and f). There are many micritic and microsparitic calcite void infills and sediment impregnations, rare Fe$\mathrm{Mn}$ replacement of amorphous organic matter/root residues, occasional thin and broad burrows, plus abundant very broad burrows. Rooting effects may be consistent with this layer being at the upper part of the studied sequence.

Tuff IIB zone

The uppermost deposits of T1-Main Trench (diamictitic units and coarse sandstones) are attributed to the Tuff IIB interval, and archaeological material is well separated vertically from that in LAS. Units L1B and L1C refer to scattered remains interpreted as background deposits. L1E was found across the entire excavated surface; totals of L1E are much lower than in the LAS and Lemuta units (see Table 3 ) because the area available for excavation at the top of the trench was much smaller due to erosion of the outcrop, which preserves larger deposits downslope. Erosional processes also explain why the L1E interval is absent in the satellite trenches, the main archaeological features of which are detailed below.

\section{The archaeological sequence of HWK EE satellite trenches}

\section{Trench $T 27$}

Adjacent to Leakey's HWK EE trench, T27 is the closest to T1-Main Trench, and is also the richest of the satellite trenches both in stone tools $(n=1959)$ and plotted fossil specimens ( $n=526)$. As in T28 and T29 (but in contrast to T1-Main Trench), contacts between claystone and sandstone deposits in T27 enabled a more straightforward identification of archaeological units during fieldwork and their correlation to lithological layers.

Lemuta units Lemuta remains were documented either in sandstones (T27L34 and T27L33) or within claystones (T27L32), apart from one single large canine (cf. Hipoppotamidae) 
within Tuff IIA (archaeological unit T27L35) (see Table 5). T27L34 sits above Tuff IIA, and is included in fine to medium sandstones with quartzite and feldspar granules (Fig. 17a). This unit is well constrained vertically (average of $\sim 7 \mathrm{~cm}$ thick), and contains the second largest lithic assemblage in T27 after T27L33, although fossils are almost non-existent (see Table 3).

T27L33 is well separated vertically by $\sim 20 \mathrm{~cm}$ of sterile sediments from the underlying T27L32, and is embedded in fine to medium augitic sandstones, which contain abundant feldspar pebbles (see Table 3). T27L33 and T27L32 are vertically indistinguishable (Fig. 17a) and can only be separated on the basis of lithological context, as T27L32 is documented within the claystone layer of the Lemuta Member. As shown in Fig. 17a, the bulk of archaeological unit T27L32 sits at the bottom of the claystone layer. An upper line of remains also exists, which in some parts of the trench is separated from the lower cluster by a sterile gap that could potentially warrant its consideration as a different archaeological unit. T27L32 contains a relatively abundant lithic assemblage, and the largest fossil accumulation beyond T1-Main Trench (Table 3), with a density of stone tools and bones of $\sim 168 / \mathrm{m}^{2}$ and $202 / \mathrm{m}^{2}$ respectively, which is one of the richest concentrations anywhere at HWK EE (Fig. 17d).

LAS units Two archaeological units (T27L31 and T27L30) were unearthed within the augitic sandstones eroding Lemuta claystones. T27L31 is mostly found within coarse to very coarse sandstones, and in some cross-sections of the trench it is not possible to vertically differentiate this unit from the top of T27L32. This unit is relatively thick $(\sim 29 \mathrm{~cm})$ and poorly defined, considering the low frequency of stone tools and fossils in T27L31 (Table 3). T27L30 is the uppermost archaeological unit of T27, and is contained within gravelly augitic sandstones. Relatively well constrained in thickness (see Table 4), horizontally this unit is primarily found in the northern part of the trench (Fig. 17b) in association with carbonates.

\section{Trench T28}

T28 is located six m to the west of T27 (see Fig. 3), and yielded seven archaeological units within the same area $(2 \times 1 \mathrm{~m})$ as excavated in $\mathrm{T} 27$.

Lemuta units The archaeological sequence starts with T28L46, which contains some scattered materials (see totals in Table 3 ) in clayey sandstones filling up the depression left by the erosion of Tuff IIA down to the LBII claystones in the southern part of the trench. Embedded within the Lemuta sandstone, T28L45 also seems to represent a background accumulation of scattered remains across a low-density deposit. T28L44 is separated by a $\sim 10 \mathrm{~cm}$ sterile gap from the underlying T28L45, and is well constrained vertically (average of $\sim 9 \mathrm{~cm}$ in thickness) at the top of the Lemuta sandstone, directly on the contact with the overlying claystone (Fig. 18).

T28L44 yielded the largest frequency of fossils $(n=64)$ and (after T28L40) stone tools $(n=79)$ in T28 (see details in Table 3). T28L43 includes all remains found within the Lemuta claystone. This archaeological unit yielded a relatively large number of well-preserved fossils (Table 3), and is vertically scattered. At the bottom of the claystones, remains are in close contact with the underlying archaeological unit (T28L44). 
LAS units The LAS interval at T28 contains three archaeological units; (from bottom up) T28L42, T28L41 and T28L40. Sitting on top of the Lemuta claystone, T28L42 is made of a thin level of remains (see totals in Table 3), which is vertically close to the overlying unit and could belong to the same depositional event. T28L41 contains a slightly larger assemblage of stone tools and better-preserved fossils alongside several natural cobbles (see Table 3 and Fig. 18d). The uppermost unit, T28L40, is sandwiched between carbonates and separated in some parts from T28L41 by a $>20 \mathrm{~cm}$ vertical gap. T28L40 has the highest frequency of stone tools $(n=117)$ at T28, despite its south end being affected by the modern erosion shaping the HWK EE outcrop.

\section{Trench T29}

Like T27 and T28, T29 was initially set out as a $2 \times 1 \mathrm{~m}$ trench at $10 \mathrm{~m}$ to the northwest of T28, but a modern erosional process dismantling the southern part of the excavation led to extending T29 to an ' $\mathrm{L}$ shape' of $3 \mathrm{~m}^{2}$. We identified three archaeological units in T29 (T29L50, T29L51 and T29L52) within 1 m of thickness (Fig. 19).

Lemuta units T29L52 is the lowermost archaeological unit excavated in T29, and was found within the lower part of the sandstone layer overlying LBII claystones. Although granulometry results indicate a silty composition for the sandstone (see Fig. 5), level T29L52 contained a substantial number of unmodified cobbles and pebbles of probable natural origin, and a relatively scarce archaeological assemblage (see counts in Table 3). Above the archaeological assemblage, large carbonates separate sandstones from the Lemuta claystone unit. A relatively thick $(\sim 20 \mathrm{~cm})$ archaeologically-sterile gap separates T29L52 from the overlying unit, T29L51. This archaeological level is vertically scattered throughout the Lemuta claystones, with material appearing from the top through the base of the claystones. With an average thickness of $\sim 46 \mathrm{~cm}$, T29L51 yielded the largest fossil assemblage (212 plotted specimens) in T29, and abundant stone tools (see Table 3).

LAS unit LAS archaeological remains in T29 are constrained to the bottom part of the unit, within a layer of dark augitic sandstone that sits upon an erosion surface that excised the underlying Lemuta claystone (see stratigraphic section in Fig. 4). As in T29L51, the lack of materials on the northwest side of the excavation is due to modern erosional processes, but Fig. 19b shows that T29L50 remains were clustered towards that part of the trench. Despite a relatively scarce fossil assemblage (see Table 3) and abundant unmodified cobbles, T29L50 yielded the largest stone tool collection $(n=533)$ in T29, resulting in a density of $\sim 251$ lithics/ $\mathrm{m}^{2}$ (see details in Table 4).

\section{Correlations between archaeological units across the HWK EE trenches}

As shown in Fig. 4 (and summarized in Fig. 20a), there is a northwest decrease in the elevation of LBII waxy claystones, and a thicker (and higher) Lemuta Member in T1 when compared to the other trenches. Although T28 is separated from T29 by a larger distance than from T27, the top of the Lemuta claystone in T28 is nearly at the same elevation as in T29, whereas such claystones are higher up towards the southeast (T27 and T1-Main 
Trench). The thicker span of LAS deposits in T1-Main Trench when compared to the rest of the trenches might be largely due to modern erosion that has removed the upper levels (including the Tuff IIB zone) in the satellite trenches. Nevertheless, there seems to be also a slight downslope trend of archaeological units towards the northwest, as shown by the conjoined artefacts from T1-Main Trench and T28 (see below), and the overall geometry of archaeological units (Fig. 20b). Thus, contextual and altimetric features of archaeological units enable correlations across the main stratigraphic intervals excavated in the four HWK EE trenches. However, with the exception of a refit from the LAS between T1-Main Trench and T28, there is a lack of physical connections between trenches, and therefore correlation attempts are mostly general (i.e. between sets of archaeological units, rather than between individual levels) and, where more specific (level to level in each trench), they should be considered as tentative.

\section{The Lemuta archaeological sequence}

Lemuta sandstone Apart from an isolated fossil within Tuff IIA (T27L35), the earliest archaeological record excavated at HWK EE is that of the Lemuta sandstones from L12 (Main Trench), T27L34 and T227L33 (T27), T28L46, T28L45 and TL28L44 (T28), and T29L52 (T29) (see Fig. 20a). L12 and T28L46 consist of scattered materials. In T29, one single unit (i.e. T29L52) spreads throughout the sandstones, while in T27 and T28 sterile gaps separate two main lines of archaeological remains; the lower one is represented by T27L34 and T28L45, and the upper by T27L33 and T28L44. Part of the material attributed to archaeological unit L10 is also within the Lemuta sandstones, although its elevation and contextual and sedimentological features seem to suggest that L10 correlates better with the upper part of the Lemuta Member (i.e. archaeological units in claystone).

Lemuta claystone T29L51, T28L43 and T27L32 can all be confidently attributed to the same archaeological interval, which is characterized by fossil and lithic remains spread throughout a claystone deposit of variable thickness $(45-50 \mathrm{~cm}$ in T29 and T28 and $30 \mathrm{~cm}$ in T27). Part of L10 at T1-Main Trench is also in a clayey context, contains abundant fossils, as within the claystone units of the satellite trenches (see Table 3 ), and its elevation is consistent with that of T29L51, T28L43 and T27L32 (see Fig. 20b). Therefore, a correlation between (at least part of) L10 at T1-Main Trench and archaeological layers within the Lemuta claystone at the satellite trenches is reasonable (Fig. 20c).

\section{The LAS archaeological sequence}

Lower archaeological units The bottom of LAS in T1-Main Trench contains two archaeological units (L8 and L6-LCHA) with materials resting on top of the Lemuta clayey sandstone, although in the case of L6-LCHA, the level spreads up well into the sandstone. In the satellite trenches, the only archaeological unit that sits directly on the Lemuta claystone is T28L42. As discussed above, T28L42 is vertically indistinguishable from the overlying T28L41, and could correspond to the same depositional event. T29L50 (T29) and T27L31 (T27) are approximately in the same position as T28L41 within the lower part of LAS, and the latter can be associated with T28L42 (which in turn could be linked to L8 and L6-LCHA). 
It is therefore plausible to correlate all of these units together at the bottom of LAS as shown in Fig. 20c.

Upper archaeological units The existence of a subsequent depositional event within LAS is evident in T28 and T27, where T28L40 and T27L30 are clearly separated by sterile gaps from the underlying units (see Fig. 20b). It is likely that this second event is not present at T29, potentially due to recent erosion. Assuming that T28L40 and T27L30 correspond to the same event, we can confidently link both units to L1-L1A in T1-Main Trench, thanks to a lithic refit between L1 and T28L40 (Figs. 21a-e). This refit set, which conjoins two lithics separated by $18.1 \mathrm{~m}$ horizontally and $1.3 \mathrm{~m}$ vertically (see details in Table 7), shows an orientation of $265^{\circ}$ and a slope of $4^{\circ}$, thus supporting the hypothesis of a slope down to the northwest, which would imply correlative layers in the satellite trenches at a lower elevation than in T1-Main Trench.

The rest of the upper archaeological sequence in T1-Main Trench is, however, more difficult to interpret due to the large amount of material throughout LAS and the discontinuity of sterile gaps separating archaeological units. L4, for instance, is considered here as part of the upper archaeological unit because of the relatively thick carbonate cement separating it from L6-LCHA and differences in the type and frequency of archaeological remains in each of these levels (see Table 3). Still, as mentioned earlier, the separation between L4 and the underlying units is fuzzier across the south of T1-Main Trench, and differentiation between the lower and archaeological sequences becomes much more difficult. Likewise, while gaps between vertical clusters suggest that $L 4$ and $L 2$ can be attributed to consecutive depositional events that took place prior to L1-L1A, there is also evidence that admixture of materials occurred throughout the stratigraphy. Figs. 21f-h illustrate this fact with two fossils that conjoin between L1 and L4, which are $4 \mathrm{~m}$ apart horizontally and $64 \mathrm{~cm}$ vertically, and whose refit line presents an azimuth $\left(260^{\circ}\right)$ consistent with that of the T28L40-L1 refit. Therefore, while acknowledging that L1-L1A, L2 and L4 correspond to a number of depositional episodes, it is also likely that there is mixing between deposits and, as a result, we conservatively consider them all to be within the same set of archaeological units, which would also include T27L30 and T28L40 (Fig. 20c).

\section{The Tuff IIB archaeological sequence}

At T1-Main Trench, archaeological material from the Tuff IIB zone is well separated vertically from the underlying LAS sequence (Fig. 20b). Three units were defined (L1B, L1C and L1E), which have no correlative levels elsewhere. Absence of the Tuff IIB zone in the satellite trenches can be confidently attributed to modern erosion, which has removed the upper deposits in T27, T28 and T29.

\section{Refit sets and the HWK EE archaeological sequence}

Refit rates are extremely low throughout in the HWK EE assemblage. However, the two refits highlighted above are extremely valuable in framing the depositional history of the assemblage and linking the satellite trenches to the T1-Main Trench. The T28L40- L1 lithic 
refit (Figs. 21a-e) is important in connecting T28 and T1-Main Trench, two trenches $18 \mathrm{~m}$ apart, and in supporting that the same LAS depositional processes took place in both areas. Equally relevant is the L1-L4 bone refit at T1-Main Trench (Figs. 21f-h), as it indicates that jumbling occurred between materials separated by over $0.5 \mathrm{~m}$ in vertical distance.

As shown in Table 7, only 13 refit sets (five bone sets and eight lithic sets) were found (two in T29, one in T27, one between T28 and T1-Main Trench, and seven within T1-Main Trench), and all of them consist of two conjoining pieces each (total number of refitted pieces $=26$ ) (see examples in Fig. 22). Given the significant time effort (total time of refit analysis $=95$ hours for lithics and 98 for fossils), there are clearly very low yield rates (one bone refit every 19.6 hours and every 11.8 hours for lithics). Considering only materials greater than $2 \mathrm{~cm}$ in length ( $n=5,171$ stone tools and 4,790 plotted bones), barely $0.15 \%$ of lithics and $0.1 \%$ fossils conjoin, which is indicative of assemblages that have undergone post-depositional disturbance.

The mean horizontal separation $(3.2 \mathrm{~m}$ ) between conjoining items is relatively high (see values in Table 7). However, this finding is influenced by the long distance of the intertrench (T28L40-L1) and inter-level (L1-L4) sets. These two sets aside, the average horizontal distance is $1 \mathrm{~m}$, and several of the conjoining fossils/stone tools are only 4-5 cm apart (see Table 7); for the latter, post-burial fracturing could be invoked. Likewise, the mean vertical distance between refits $(30 \mathrm{~cm})$ is reduced to $10 \mathrm{~cm}$ when the two conjoin outliers are removed. Orientation of refit lines are considerably patterned around the $90^{\circ}-270^{\circ}$ trend, which might hint to the existence of an E-W flow (see discussion below). The mean slope of the refit lines is $13^{\circ}$, which is relatively high and generally supports the dipping trend observed in some archaeological units (see Figs. 10, 13, 15).

\section{Density patterns across the HWK EE trenches}

Most of the HWK EE archaeological assemblage derives from T1-Main Trench (see counts in Table 3), due to the larger size of the excavation at this trench $\left(49.2 \mathrm{~m}^{3}\right.$ of sediments excavated throughout a $5.1 \mathrm{~m}$ thick section in an area of up to $32.5 \mathrm{~m}^{2}$ : see Table 4). However, the highest density of remains per $\mathrm{m}^{2}$ and per $\mathrm{m}^{3}$ is found at T29 (Fig. 23c) and T27 (Fig. 23d), respectively. Within these trenches, archaeological units that contain the highest density of material per $\mathrm{m}^{2}$ (Fig. 23a), and per $\mathrm{m}^{3}$ (Fig. 23b) are T27L32, T27L33 and T27L34, followed by T29L50.

Stone tool densities are far greater than fossil densities (Table 4). However, density calculations of lithic artefacts are irrespective of specimen size, while those for fossils do not include the majority of specimens recovered from sieving. The abundance of small $1<20$ $\mathrm{mm}$ ) lithic debris in the assemblage (see discussion below), suggests that fossil: lithic density ratios should be considered with caution. Regardless, Figs. 23c-d demonstrate that fossil density was greatest in T29 and T27, in agreement with stone tool patterns.

Figs. 23e-j explore distributions of remains across stratigraphic intervals and lithofacies (see also SOM S6), as density calculations per archaeological unit (Fig. 23a-b) could be biased due 
to the poor definition of contacts between archaeological levels. With $\sim 283$ remains/ $\mathrm{m}^{2}$, the LAS assemblage in T29 is the densest across all HWK EE trenches (see Fig. 23e and SOM S6), although the Lemuta Member in T27 is denser in volume estimates ( 2484 remains/ $\mathrm{m}^{3}$ ) (Fig. 23f). Density of remains in T29- LAS and T27- Lemuta is followed by the LAS interval in T1-Main Trench, and Lemuta in both T29 and T1-Main Trench (Figs. 23e-f).

Density of remains per lithofacies (Fig. 23g-h) shows a clearer pattern; the Lemuta clay yielded the highest density per area excavated (197 remains/ $\mathrm{m}^{2}$ ), followed by the Lemuta clay/ sandstone (i.e. L10 in T1-Main Trench; see values in Table 4), the Lemuta sandstone ( 101 remains $/ \mathrm{m}^{2}$ ) and the LAS sandstone $\left(\sim 98 / \mathrm{m}^{2}\right.$ ) (see Fig. $23 \mathrm{~g}$ and values in SOM S6). In terms of estimated volume (Fig. 23h), Lemuta sandstone exhibits by far the highest density (1283 remains/ $\left.\mathrm{m}^{3}\right)$, followed by the Lemuta claystone ( 514 remains/ $\mathrm{m}^{3}$ ) and LAS sandstone ( $\sim 68$ remains $/ \mathrm{m}^{3}$ ) (SOM S6).

When all material is pooled together within the three main stratigraphic intervals preserved in HWK EE (Figs. 23h-i), it is observed that there is slightly higher density $/ \mathrm{m}^{2}$ of stone tools in LAS ( 97 remains $/ \mathrm{m}^{2}$ ) than in Lemuta (86 remains $/ \mathrm{m}^{2}$ ), with the opposite pattern for the density of fossils ( 22 remains $/ \mathrm{m}^{2}$ and $34 / \mathrm{m}^{2}$, respectively). The Tuff IIB interval has the lowest density of both stone tools $\left(11 / \mathrm{m}^{2}\right)$ and fossils $\left(3 / \mathrm{m}^{2}\right)$. When lithics and fossils are combined, the Lemuta and LAS contain similar quantities of archaeological remains (120 remains $/ \mathrm{m}^{2}$ and $119 / \mathrm{m}^{2}$, respectively), and thus stratigraphic interval productivity per $\mathrm{m}^{2}$ is essentially identical (Fig. 23i). Productivity per volume yields a slightly higher density of remains for the Lemuta Member (Fig. 23j), but since this is largely inferential (i.e., $\mathrm{m}^{3}$ of sediments are unavailable for most subsamples), equal productivity of Lemuta and LAS assemblages as indicated by density/ $\mathrm{m}^{2}$ is emphasized here.

\section{Environmental evidence}

\section{Diatoms}

Diatoms were recorded in samples \#93 (T29), \#66 (T28), and \#81, \#84 and \#87 (T1-Main Trench; see position in Fig. 5a). However, the only sample with quantifiable diatoms was the Lemuta black coarse sandstone sample \#84 (Table 8), which had low diatom abundance (1.9 $\times 106$ valves/g). Diatoms showed low dissolution (10\% of valves) and moderate fragmentation (complete valves: 40\%; fragmentation index: 0.5 ), suggesting moderately unstable physical conditions. Species diversity was low, and the sample contained 21 morphotypes. Nitzschia amphibia, Gomphonema sp., Nitzschia sp., Pseudostaurosira brevistriata, Staurosirella cf. pinnata and Cocconeis cf. placentula were the dominant morphotypes (Table 8, Fig. 24).

Predominance of the genera Nitzschia and Gomphonema indicates a freshwater pool. The dominance of $N$. amphibia and the analysis of the whole assemblage suggests mesooligotrophic conditions, intermediate values of conductivity $(200-700 \mu \mathrm{S} / \mathrm{cm})$ and $\mathrm{pH}$ between 7.0 and 8.0 (Gasse and Tekaia, 1983; Gasse et al., 1995). Nitzschia amphibia is mainly benthic or epiphytic. Other taxa recovered from this sample, such as Nitzschia cf. epiphytica and $C$. cf. placentula, have been recorded as epiphytic species of the littoral zone 
of pools, wetlands and rivers, whereas $P$. brevistriata and S. cf. pinnata are planktonic and characteristic of the littoral zone of shallow freshwater ecosystems (Gasse et al., 1983).

\section{Phytoliths}

Phytolith abundance varied across the 30 samples analysed, with a minimum number of identifiable phytoliths $(n=50)$ ranging from 30,000 to $1,200,000$ phytoliths /g of sediment. Highest phytolith content in all trenches was in Lemuta sandstone samples (Table 9 and Fig. 25a). Weathering rates varied significantly, and samples yielding a higher rate of dissolution were those from LBII and LAS (sample \#48 from T27 and samples \#16 and \#31 from T1-Main Trench), with values above $60 \%$ in some samples (Table 9). Phytolith morphotypes indicate the presence of both monocotyledonous (mostly Poaceae) and dicotyledonous plants (Table 9 and Fig. 25a).

Lower Bed II claystone Three samples from T28, T27 and T1-Main Trench corresponded to the LBII waxy claystone lithofacies (Table 9), out of which only sample \#48 (T27) could be morphologically interpreted (>50 phytoliths) (Table 9 and Fig. 25a). This sample was dominated by rondel short cells from the Poaceae family. Elongate and spheroid morphotypes with no decorated and decorated surface (echinate) were also abundant (Fig. 25b). The spheroid echinate morphotype is usually assigned to the Arecaceae family.

Lemuta sandstone With the exception of samples \#51 (T27) and \#84 (T1-Main Trench), Lemuta sandstones yielded the best preservation of silica micro-remains (phytoliths, diatoms and sponge spicules) (Table 9). These samples also contained phytoliths in anatomical connection (Fig. 25c-d).

Spheroid and ellipsoid morphotypes with echinate surface (common in palms) (Fig. 25e-f) were identified in all samples, being most abundant in westernmost T29 (sample \#93, 33\%) and least common in easternmost T1-Main Trench (samples \#81 and \#87, <22\%) (Table 9 and Fig. 25a). Bulliform and trichome phytoliths (which are characteristic of Poaceae leaves) and elongates (with dentate margin characteristic of the inflorescence of the same plants) were also identified (Figs. 25g-j). Other recognizable morphotypes from the Poaceae family were saddle short cells from the C4 Chloridoideae subfamily (more abundant in the two western trenches; see Figs. 25k-I), rondels (mostly in samples \#93 and \#81; see Figs. 25m-o), and bilobates (Fig. 25p). Characteristic sedge phytoliths (Fig. 25q) and phytoliths from dicotyledonous plants (<18\%: Fig. 25r-u) were also identified.

Lemuta claystone and Lemuta clayey sandstone None of the five Lemuta claystone samples presented a sufficient number of recognizable phytoliths to undertake a vegetation interpretation. The few morphotypes recognized corresponded mostly to rondel short cells from the Poaceae family and elongates. Palm phytoliths were identified only in sample \#96 (T29) and \#36 (T27). The two Lemuta clayey sandstone samples were similarly poor; elongates and irregulars with verrucate surface and rondels from the Poaceae family were the only morphotypes identified.

LAS Only two samples (\#16 and \#31) out of the 13 LAS samples in T1-Main Trench presented enough morphologically- identifiable phytoliths for study (Table 9 and Fig. 25a). The most 
common morphotypes in both samples are Poaceae rondel short cells. Bulliforms and trichomes from Poaceae leaves were also identified. Sample \#16 yielded higher abundances of Poaceae phytoliths, whereas sample \#31 had more spheroids with no decorated surface, most common in dicotyledonous plants. Sample \#31 also contained palm phytoliths and some irregulars (Fig. 25v).

\section{Lithic materials}

\section{Unmodified lithics}

While HWK EE sediments are usually fine-grained (see Table 2 and description above), significant numbers of unmodified lithics (breakdowns in Table 3) were observed throughout the deposits, normally in matrix-supported contexts. In some archaeological units, cobble-sized unmodified lithics were documented in clusters (Figs. 26a and 26c), often alongside flaked and battered artefacts of similar dimensions. Field observations of clustering are supported by geostatistical analysis of T1-Main Trench spatial patterns, which confirm non-random distributions of unmodified lithic materials throughout the sequence (Figs. 27a-b). This large quantity of unmodified material across the HWK EE trenches $(n=4,339$, weighing a total of $436.35 \mathrm{~kg}$ ), can be classified into two main size groups (Fig. $26 \mathrm{~b})$, pebbles $<28 \mathrm{~mm}$ in length $(60.1 \%$ ) and clasts $>55 \mathrm{~mm}$ (see Table 10). Pebble-sized clasts are mostly made of feldspar (51.7\%), followed by quartzite (30.6\%) and lava (16.5\%) (see absolute frequencies in Table 11). A predominance of feldspar is accentuated when Jenks' class 1 (i.e. lithics $<28 \mathrm{~mm}$ ) is considered, indicating that the smallest fraction of natural clasts is mostly made of this mineral (61.7\%). In contrast, unmodified cobbles (i.e. clasts $>64 \mathrm{~mm}$ ) are overwhelmingly dominated by lava fragments of variable composition $(96.6 \%)$, a pattern that is maintained when clasts from Jenks' class $3(55-72 \mathrm{~mm}$ ) are added. In summary, a tight pattern emerges where unmodified materials are characterised by $<28$ $\mathrm{mm}$ pebbles of feldspar, and $>55 \mathrm{~mm}$ clasts (mostly cobbles) of lava -mostly phonolites, trachytes and basalts- (see lithological descriptions in McHenry and de la Torre, submitted).

\section{Stone tools}

The HWK EE stone tool assemblage is substantial ( $n=18,107$ artefacts; see breakdowns in Table 3), and totals $456.36 \mathrm{~kg}$. Most lithics belong to Jenks' class 1 (i.e. smaller than $16 \mathrm{~mm}$ ), which constitutes $63.98 \%(n=11,577)$ of the assemblage (see details in Table 10), although in terms of weight most of this nearly half a ton of modified artefacts are flaked or battered tools (with a combined weight of $400.12 \mathrm{~kg}$ ). As shown in Table 3, detached materials are dominant in all assemblages, followed by flaked and battered artefacts.

Quartzite dominates the assemblage in terms of artefact frequency ( $n=15,552$; see Table 12), due to abundance of small debitage pieces (see also Table 11). Despite its high absolute frequency, quartzite debitage makes up only $41 \mathrm{~kg}$ out of the nearly half a ton of lithics in the assemblage, and even when considered alongside flaked/ battered artefacts of the same raw material ( $n=637$ stone tools weighing $114.82 \mathrm{~kg}$; see Table 12), quartzite is not the best represented in the assemblage in terms of the amount of raw material. Lava artefacts 
almost triple the input of quartzite with $296.63 \mathrm{~kg}$ (282.16 kg of battered/flaked tools plus $14.17 \mathrm{~kg}$ of debitage; see Table 12), despite their dramatically lower frequency $(n=1,488$ lava artefacts). While feldspars are abundant among unmodified lithics (Table 12), they are negligible among stone tools, and chert is the only other relevant modified raw material apart from lava and quartzite. Although chert is insignificant numerically $(n=340)$ and by weight $(2.1 \mathrm{~kg}$ ) (Table 12) when compared to lava and quartzite, this raw material is important taphonomically (see below) and technologically (de la Torre and Mora, submitted) in the HWK EE assemblage.

Technological aspects of the HWK EE assemblage are discussed elsewhere (Arroyo and de la Torre, submitted; de la Torre and Mora, submitted; Pante and de la Torre, submitted), although it is relevant to stress here the lack of handaxes and other indicators of Acheulean technology. The HWK EE lithic collection is characterised by cores and flakes, with variable frequencies of retouched tools and battered artefacts. Thus, the entire collection of HWK EE (with the possible exception of the Tuff IIB archaeological units at T1-Main Trench) is here attributed to the Oldowan sensu lato, and issues concerning its attribution to the classic Olduvai Oldowan or Developed Oldowan are considered elsewhere (de la Torre and Mora, submitted; Proffitt, submitted).

\section{Unmodified and modified lithics in the HWK EE sequence}

Absolute frequencies of natural and modified lithics (Fig. 28a) are strongly associated as shown by a chi-squared test $\left(X^{2}(72)=4977.14, p<0.0001\right)$. This indicates that those archaeological units with higher frequencies of artefacts also contain statistically significant higher numbers of unmodified cobbles and pebbles. As shown in Fig. 28b, clustering of archaeological units in FCA is not by trench, and so Figs. 28c-e explore distributions of natural and modified lithics in each trench per stratigraphic member. Chi-squared results are again highly significant $\left(X^{2}(24)=2255.45, p<0.0001\right)$, with Fig. 28e showing clear association between Lemuta units and pebbles (most of which are $<20 \mathrm{~mm}$ feldspars, as discussed above).

Figs. 28f-h explore the distributions of natural and modified lithics in each lithological context, where a statistically significant relationship is also strongly supported $\left(X^{2}(15)=\right.$ 1961.66, $p<0.0001$ ). Fig. 28g highlights the low relative frequency of pebbles in the LAS sandstone, while Fig. 28h suggests an association of larger pieces (both cobbles and battered/ flaked artefacts) with the LAS sandstone, and of pebbles with the Lemuta Member, particularly the sandstone units. Further consolidation of data is explored in Figs. $28 \mathrm{i}-\mathrm{I}$, in which natural and modified lithic distributions are compared by stratigraphic member irrespective of their trench location.

Chi-squared tests comparing the four types of objects (cobbles, pebbles, flaked/battered and detached) per stratigraphic member are highly significant $\left(X^{2}(6)=1857.44, p<0.0001\right)$, and remain so when the comparison is simplified to archaeological versus natural pieces ( $X^{2}$ $(2)=452.19, p<0.0001)$. Residuals indicate again the low relative frequency of pebbles in the LAS Member compared to an overabundance in Lemuta (Fig. 28j), and higher numbers of archaeological materials in LAS when compared to Lemuta (Fig. 28I). 
While relative frequencies confirm that there is a co-occurrence of stone tools and unmodified lithics throughout the sequence, size distributions of these two categories are different; the chi-squared test confirms $\left(X^{2}(4)=2499.55, p<0.001\right)$ that there is a significantly higher than expected proportion of larger unmodified lithics (Fig. $28 \mathrm{~m}$ ), a trend that is reversed for stone tools (Fig. 28n). In principle, this pattern might look predictable on the basis of greater fragmentation (and therefore smaller pieces) among the stone tools. However, further investigation of the relationship between size classes and intervals indicates strong statistical differences $\left(X^{2}(5)=1859.59, p<0.001\right)$ between Lemuta and LAS unmodified lithics; thus, Fig. 280 shows that the Lemuta unmodified lithics follow a different pattern, where the number of smaller pieces is significantly higher than expected. Further exploration of three-dimensional data (i.e. length, width and thickness) through shape analysis (Fig. 28p) reveals that, while the numbers of observed stone tools in Sneed and Folk's classes are not significantly different from the expected values, unmodified lithics tend to be much more compact $\left(X^{2}(9)=291.56, p=0.001\right)$ (see raw data in SOM S7).

In addition to comparisons of frequencies, dimensions and shapes of objects (Fig. 28), spatial tests also indicate that a clear relationship between stone tools and unmodified material exists, with clustering occurring in the same areas for both types of items (Fig. 27c). Thus, all lines of evidence suggest that human-made and unmodified lithics co-occur in all HWK EE trenches, and -based on the case of T1- Main Trench- that both types of objects are clustered and spatially associated.

\section{Fossil remains}

The HWK EE bone assemblage contains 29,808 items, of which 29,115 were studied. The collection contains 6,017 plotted specimens and 23,791 small fragments (usually $<20 \mathrm{~mm}$ ) recovered during sieving (see Table 3 ). As shown in Table 10, most of the plotted fossil fragments belong to Jenks' class $1(n=3,173)$, which thus brings the number of specimens $<33 \mathrm{~mm}$ to 26,964 . Bone fragments ranging from 34 to $62 \mathrm{~mm}$ are relatively abundant $(32.7 \%)$, and the smallest fraction is that of fossils over $83 \mathrm{~mm}(3.83 \%)$, although, as shown in Fig. 9, relatively complete specimens were also found across the HWK EE trenches. The vast majority of fossils were recovered from LAS, followed by the Lemuta interval (Table 13). Excavation of the Tuff IIB interval did not produce a large fossil collection.

The HWK EE fossils are well preserved overall and were probably buried shortly after deposition. The majority of mammal bones in the assemblage are not weathered beyond stage 1 of Behrensmeyer's (1978) weathering stages, and very few are weathered beyond stage 2 (Table 13). The LAS interval showed the least amount of weathering, while the Tuff IIB interval exhibited the most. Quick burial was likely facilitated by fluvial depositional processes, which would have served to preserve the cortical surfaces of fossils in the assemblage. Fossils in the Lemuta interval had the highest percentage (57.3\%) of wellpreserved cortical surfaces. Lemuta fossils also exhibit the lowest proportion of specimens with major rounding associated with fluvial abrasion, while those in the LAS interval have the highest proportion (see Table 13). 
Bone surface modifications indicative of carcass consumption are abundant in the HWK EE fossil assemblage and occur in all three intervals (see a detailed analysis of these feeding traces in Pante et al., submitted). The feeding traces of hominins, carnivores and crocodiles are found on the surfaces of fossils in the assemblage. Mammalian carnivore tooth marks are the most common modification, followed by percussion marks, cut marks and then crocodile tooth marks. Some fossils exhibit both hominin and carnivore feeding traces indicating that they were occasionally feeding from and competing for the same carcasses at the site.

The HWK EE fossil assemblage is taxonomically rich, with a minimum of 78 individuals represented (Table 14). The LAS interval has both the greatest number of individuals and species richness, followed by Lemuta. Overall, the assemblage is dominated by grazers like alcelaphines, antilopines, and equids that indicate open grassland habitats throughout the LAS and Lemuta intervals (see further details in Bibi et al., submitted this volume and Rivals et al., submitted). The presence of fish, Hippopotamus and Crocodylus suggests abundant water at the site. It is worth noting that the large sample of crocodile teeth $(n=284)$ is overwhelmingly concentrated in LAS $(95.4 \%)$, with a very marginal presence $(n=14)$ in Lemuta sediments. Mammalian carnivores are rare overall, but more common in the LAS interval. Most are bone crunching specialists, such as canids and hyaenids. The lone hominin fossil is the root of a premolar, which could not be identified to genus or species.

Statistical tests indicate covariation of fossils and lithics throughout the sequence; cooccurrence is very strong $\left(X^{2}(48)=2292.54, p<0.0001\right)$ when frequencies are compared by archaeological unit (see also Fig. 29a), although some units associate particularly with stone tools (e.g., L1 and T29L50), unmodified materials (e.g., L6-LCHA) or bones (e.g., L10) (Fig. 29b). This correlation is maintained when fossils are compared to lithics as a whole $\left(X^{2}(24)\right.$ $=1659.67, p<0.0001)$. A statistically significant association $\left(X^{2}(8)=862.85, p<0.0001\right)$ also exists between fossils and lithics in each trench/ interval (Fig. 29c), although relatively higher frequencies of bones in Lemuta and of stone tools in LAS are observed (Fig. 29d).

\section{Post depositional features}

Stone tool edge damage

Roundness was studied in a sample of 5,877 stone tools from the entire HWK EE lithic assemblage, which includes $100 \%$ of artefacts $>20 \mathrm{~mm}$ and a sample from those below 20 $\mathrm{mm}$ in length (see counts in Table 10). As shown in Table 15, 78.8\% $(n=4,630)$ of the analysed sample preserves fresh edges, and frequencies of medium $(3.8 \%)$ or severe $(0.9 \%)$ edge rounding are low (see also Fig. 30a).

Distribution of roundness percentages across the trenches (Fig. 30b) presents statistically significant differences $\left(X^{2}(9)=54.49, p<0.0001\right)$, with T27 yielding the highest frequency (92.7\%) of fresh artefacts, and T1-Main Trench the lowest $(77.4 \%)$. The Lemuta interval preserves a larger number of fresh artefacts $(88.8 \%)$ than LAS $(76.6 \%)$, while the Tuff IIB interval contains the highest frequencies of medium $(4.6 \%)$ and severe $(3.2 \%)$ rounding - 
differences are highly significant according to the chi-squared test $\left(X^{2}(6)=96.05, p<0.0001\right.$; see counts in Table 15 and distribution in Fig. 30c). Statistically significant differences $\left(X^{2}(9)\right.$ $=96.64, p<0.0001)$ can also be observed in lithofacies, with higher frequencies of fresh artefacts in claystone $(93.7 \%)$ and clayey sandstone (86.5\%), than in sandstone $(77.1 \%)$ and diamictite (71.1\%) (Fig. 30d).

Roundness indices also vary according to features of stone tools; lava (78.5\%) and metamorphic (79.6\%) fresh artefacts are substantially more abundant than chert $(62.6 \%)$, while the frequency of slightly rounded stone tools in chert is significantly higher (28.3\%) than for lava (17.3\%) and metamorphic $(15.8 \%)$ artefacts $\left(X^{2}(6)=44.02, p<0.0001\right.$; see values in Table 15 and Fig. 30e). Fig. 30f shows progressive descent in the frequency of fresh artefacts according to size (from $85.5 \%$ of fresh artefacts $>100 \mathrm{~mm}$ to $75.7 \%$ in those $<20$ $\mathrm{mm}$ ), and a reverse tendency in both slightly rounded (from $18.9 \%$ in the $<20 \mathrm{~mm}$ length class to $10.8 \%$ in those $>100 \mathrm{~mm}$ ) and medium rounded (from $4 \%$ in the $<20 \mathrm{~mm}$ class to $2.4 \%$ in those $>100 \mathrm{~mm}$ ) stone tools $\left(X^{2}(6)=16.86, p<0.009\right)$. A similar pattern is observed in roundness distributions according to weight, as the frequency of fresh edges in heavier artefacts $(88.2 \%)$ is considerably higher than in artefacts between $5-50 \mathrm{~g}(76.9 \%)$ and in the lighter stone tools (76.5\%) (Fig. 30g) $\left(\mathrm{X}^{2}(6)=76.40, p<0.0001\right)$. Likewise, cores and pounding tools bear comparatively fresher edges than detached pieces (Fig. 30h), with differences across the sample that are statistically significant $\left(X^{2}(3)=81.78, p<0.0001\right)$.

Presence/ absence of edge microfracturing was recorded in 5,017 stone tools, of which 33\% presented this type of damage (Table 15). Frequencies of edge microfracturing are similar in the Tuff IIB and LAS intervals (31.6\% and 34.2\%, respectively) and lower in Lemuta (27.8\%), and there are statistically significant differences $\left(X^{2}(2)=13.55, p<0.001\right)$ between the three samples. Artefacts with edge microfracturing are more abundant in diamictite $(39.3 \%)$ and sandstone units (34\%) than in claystone $(28.5 \%)$ and clayey sandstone $(26.3 \%)$, yielding statistically significant differences across the sample $\left(X^{2}(3)=14.76, p<0.002\right)$. Whilst lava and metamorphic artefacts show similar proportions of microfracturing $(37.8 \%$ and $30.3 \%$, respectively), differences per raw material are statistically significant $\left(X^{2}(2)=159.12, p\right.$ $<0.0001)$, and chert shows a dramatically higher frequency of artefacts with microfractures (70.2\%) (see counts in Table 15).

\section{Stone tool size distribution}

Tables 10 and 11 summarize metrics for the entire HWK EE assemblage, and demonstrate the overwhelming predominance of artefacts of small dimensions. Stone tools below $1 \mathrm{~g}$ comprise $50.7 \%(n=9,176)$ of the assemblage, and combined with those ranging between 1$5 \mathrm{~g}(n=5,593)$, reach $81.6 \%$ of the entire collection. Interestingly, these two weight groups (the lightest), are followed by the heaviest (i.e. more than $50 \mathrm{~g}$ ), which includes $7.8 \%$ $(n=1,423)$ of all stone tools (see also Fig. 31a).

Maximum length follows a similar pattern; artefacts with length $\leq 30 \mathrm{~mm}$ (Jenks' classes 1 and 2) predominate massively (86\%; $n=15,561$ ), of which most are debris $<20 \mathrm{~mm}$ (see values in Table 10). As illustrated in Fig. 31b, the first two length intervals (i.e. $<20 \mathrm{~mm}$ and 
20-39 $\mathrm{mm}$ ) account for $89.9 \%$ of stone tools, with decreasing frequencies in the rest of groups (see also Fig. 31c).

Analysis of length histograms (Fig. 32) reinforces the existence of a general trend with a high number of small artefacts and a sharp drop in frequencies as length increases. However, some divergence is observed when stratigraphic intervals, lithofacies and raw materials are compared. Such differences were investigated statistically (SOM S8 and SOM S9), which confirmed that datasets do not have a normal distribution (Shapiro-Wilk and KolmogorovSmirnov tests), and that some of the datasets compared in Fig. 32 (e.g. raw materials and intervals) are drawn from different distributions (two-sample Kolmogorov-Smirnov and Mann-Whitney U tests).

ECDF graphs indicate clear divergence of lava length distributions when contrasted to metamorphic and chert artefacts (Fig. 31e), which is due to significantly higher numbers of large lava artefacts. Differences are also evident when the Tuff IIB interval assemblage is compared to Lemuta and LAS (Figs. 31f-g), as the uppermost interval contains comparatively higher proportions of large artefacts. In addition, length distribution differences can also be observed between Lemuta and LAS; the chi-squared test $\left(X^{2}(5)=749.7, p<0.0001\right)$ strongly suggests differences between the two samples, and the Fisher test $(p<0.0001)$ and the residues (Fig. 31d) point to the significant deficit of $<20 \mathrm{~mm}$ artefacts in LAS when compared to the Lemuta units, which is reversed in stone tools with $20-39 \mathrm{~mm}$ of length.

Given the overwhelming predominance of lithic artefacts $<20 \mathrm{~mm}$, further analysis of size distribution within this group is illustrated in Figs. $31 \mathrm{~h}-\mathrm{j}$ and Fig. 32b. Within this sample $(n=12,923), 83.9 \%$ of lithics range between 6 and15 $\mathrm{mm}(6-10 \mathrm{~mm}=5,711$ pieces; $11-15$ $\mathrm{mm}=5,135)$, while both ends of this length interval $(1-5 \mathrm{~mm}$ and $16-19 \mathrm{~mm}$ ) are more sparsely represented (1.1\% and $14.9 \%$, respectively). Chi-squared and ANOVA tests (SOM S10) for $<20 \mathrm{~mm}$ artefact length per raw material and across all stratigraphic intervals, returned highly significant values $(p<0.05)$, hence suggesting differences in size distributions within the entire assemblage (see also Fig. 32b). When the analysis is narrowed to the two main stratigraphic intervals (LAS and Lemuta) and comparisons are based on the four subgroups within the $<20 \mathrm{~mm}$ length class (Figs. 31i-j), chi-squared tests help clarify such disparities. Thus, statistically significant differences in length distribution are observed according to lithofacies $\left(X^{2}(6)=93.85, p<0.0001\right)$, with considerably higher frequencies of the largest size bin $(16-19 \mathrm{~mm})$ in sandstone units. Differences are also strong $\left(X^{2}(3)\right.$ $=252.14, p<0.0001$ ) when the LAS and Lemuta intervals are compared, which highlight higher frequencies of $16-19 \mathrm{~mm}$ objects in LAS (consistent with the previous lithofacies comparison), and a deficit of 6-10 $\mathrm{mm}$ pieces in LAS when contrasted to Lemuta.

\section{Orientation and fabric analysis}

Orientation data of all measured items $(n=1,101)$ and those with le $>1.6(n=738)$ (see counts in SOM S11) were compared using four levels of analysis, from the most specific (archaeological unit; Fig. 33b), to trench/interval/lithology (Fig. 33c), lithofacies/interval (Fig. 34a) and, finally, stratigraphic interval (Fig. 34b). Uniformity and unimodality were tested in 
these datasets (SOM S12), and mean vectors (Fig. 33a) and Curray's L values (SOM S13) were examined.

Orientation data suggest a NE-SW pattern for the mean vectors (Fig. 33a), although rose diagrams and statistical results generally show plurimodal distribution of orientations in each of the datasets. Despite this general plurimodal trend, clear main modes are observed in the rose diagrams of T29L51 (T29-Lemuta claystone), T27L32 (T27 Lemuta claystone), L10 (T1-Lemuta clayey sandstone, Lemuta clayey sandstone), L8, L4, L2, L1A-L1, T28 LAS sandstone, Lemuta sandstone and Lemuta claystone (see Figs. 33 and 34). Of these, only six datasets have sample sizes large enough ( $>15$ items) to deem these results significant, namely T27L32 (T27-Lemuta claystone) and Lemuta claystone (NW-SE mode), L1A-L1 and L2 (NE-SW mode), L10 (T1-Lemuta clayey sandstone) and L4 (W-E mode). Interestingly, these different orientation modes come from archaeological levels in the same trench (T1-Main Trench).

Overall, there is no general trend for the entire site or even particular trenches, and a plurimodal -yet not entirely random- distribution of orientations dominates. However, the comparison of mean vectors with trends described above shows a preference for W-E and NE-SW orientation modes. To investigate these patterns further, orientation data per interval were compared across the HWK EE outcrop in $2 \mathrm{~m}^{2}$ sectors (Fig. 35a), and more widely across four separate areas of the HWK EE outcrop, namely T1 Area 1 (northeast part of T1-Main Trench), T1 Area 2 (southwest of T1-Main Trench), T27, and T28 (Fig. 35b and 35c). The Shapiro-Wilk test established the non-normality of distributions in all datasets with the exception of T27 LAS ( $p=0.8114)$ and T28 LAS $(p=0.1646)$, and Kolmogorov-Smirnov and Mann-Whitney $U$ tests were used to establish whether particular orientation sets differed from one another. Results of both tests (SOM S14) unambiguously show that the null hypothesis of samples being drawn from the same distribution cannot be rejected, and this similarity of orientation distributions across datasets is supported by the Tukey HSD (SOM S14), exact permutation, and Watson-Wheeler (SOM S15) tests.

A visual inspection of Fig. 35b shows the strong similarities between the main mode of T1 Area 1, and the secondary modes of T1 Area 2 and T28 (see bearings in Table 16). In this same LAS interval, primary modes of T27 and T28 are practically identical (see Fig. 35b and bearings in Table 16). Lemuta interval rose diagrams (Fig. 35c) also show similarities: primary modes at T28 and T1 Area 1 are indistinguishable and, more remarkably, the two main modes in both T27 and T1 Area 2 are consistently similar (primary mode of T27 and secondary mode of T1 Area 2; secondary mode of T27 and primary mode of T1 Area 2).

Results of fabric analysis are shown in Fig. 36. Although Curray's L values (SOM S16) are generally not considered an accurate indicator of bi- or plurimodal orientation distributions, when paired with high $p$ values, they suggest no strong linear tendencies in any of the HWK $\mathrm{EE}$ datasets. The mean vector $\mathrm{R} \%$ index also shows little to no indication of linear orientations (SOM S16). The same pattern occurs in K (shape) values (SOM S17), which in all cases are well below 1 . The $C$ (strength) parameter shows low to moderate strength fabrics, and higher values correspond with low sample sizes (apart from T27L32 and L2, which reach $C$ values $>2.5$ ). When isotropy (IS) and elongation (EL) indices (SOM S18) based on the 
eigenvectors are represented on Benn's diagrams (Fig. 36), a strong, uniformly planar tendency with very little isotropy of fabrics is observed. The only exception is T29L51, which shows significantly more linear fabrics and a higher degree of isotropy. However, due to the low sample size $(n=26)$, this cannot be considered an accurate indicator of the nature of the fabrics in this particular archaeological unit.

\section{Spatial distribution}

Considering the archaeological level as the minimal unit of analysis, T1-Main Trench artefact density heat maps (Figs. 37, 38a-b, SOM S19- S22) suggest peaks of intensity in most of the analysed datasets. This visual inspection is confirmed by the Clark and Evans test (SOM S23), which indicates clustering of items in most datasets (values <0.9 in 176 out of 197 analysed samples; see SOM S23). Results of this nearest neighbour analysis show that archaeological unit L4 has the least spatial randomness, whereas the only indication of regular distribution is in L10; in this archaeological unit, Jenks' length class 5 of both fossils ( $R=1.5543$, $p=0.005024)$ and stone tools $(\mathrm{R}=1.1699, p=0.02927)$ suggests a pattern of regular distribution for larger objects. Unit L10 is also the one with most spatial randomness (11 datasets > 0.9; see SOM S23).

The Ripley's K-function allowed the number of datasets to be narrowed down significantly with clustering, identifying datasets where random distribution was possible at some scales. Results (SOM S24) generally indicate that smaller artefacts (Jenks' classes 1 and 2 in fossils, stone tools and unmodified lithics) show stronger clustering tendencies (with the exception of archaeological unit L10), whereas large artefacts (Jenks' classes 4 and 5) tend to be more randomly distributed over the excavation surface in each archaeological unit. L10 yielded the largest difference between lithic and fossil distributions; while fossils are randomly distributed, lithics are significantly clustered, even when compared to other archaeological units (see Fig. 37 and SOM S23).

Spatial analysis also considered the stratigraphic interval as the unit of study: as shown in Fig. 38c, LAS materials tend to distribute across the NE area of T1-Main Trench, whereas the Lemuta assemblage's highest peak occurs in the south side of the trench, with additional concentrations in the middle and northern areas. Results of the Clark and Evans test (SOM S25) indicate a tendency towards random distribution for the LAS assemblage ( $R$ ranging 0.8-0.83) and Lemuta fossils $(R=0.88112)$, in clear contrast to the Lemuta lithic datasets $(R<0.75)$, which are more clustered.

\section{Discussion}

Characterisation and palaeoenvironmental interpretation of the HWK EE sedimentary sequence

The HWK EE sedimentary succession (Figs. 4 and 20) reveals five depositional intervals, all separated by disconformities, one of which is a major incision surface. The Lower Bed II 
sequence comprises: (1) a claystone unit at the base; (2) a unit of multi-storeyed Lemuta sandstone layers, attributable to the middle Lemuta tongue, otherwise designated Tuff IIA (Hay, 1976); and (3) a Lemuta claystone above Tuff IIA. Within the Middle Bed II sequence is contained: (4) a thick sequence of multi-storeyed augitic sandstones that form the LAS unit; succeeded by (5) reddish diamictite sediments and red claystone layers, which are part of the Tuff IIB zone.

Lower claystone unit (1) Comprises two lake-parasequences (Stanistreet, 2012). The lower lake-parasequence is characterized by a massive olive waxy claystone $(>30 \mathrm{~cm})$ topped by a rooted and burrowed layer of $<20 \mathrm{~cm}$ thickness. The higher lake-parasequence comprises solely a massive olive waxy claystone up to $40 \mathrm{~cm}$ thick, truncated by a pronounced disconformity, displaying obvious channelforms, on top of which the Tuff IIA Lemuta sands were deposited. The unit records two rises and falls of Palaeolake Olduvai. Initially the lake occupied the area, depositing a thick unit of clay, but retreated, allowing colonization of the resulting exposed lake flat by plants and burrowing invertebrates. A second expansion of the lake resulted in deposition of the higher clay layer, but substantial withdrawal of Palaeolake Olduvai resulted in major fluvial erosion prior to Lemuta sand deposition.

Lemuta sandstone unit (2) Tuff IIA unit, comprises multi-storeyed erosionally based sandstone layers, mostly well sorted. However, the sandstone at the top of the unit in Trenches T1 and T27 sits on an erosion surface cutting down deeply into the underlying sandstone and is pronouncedly clayey in nature, probably due to the erosion and elimination of intervening clay units and incorporation of clay into the uppermost sand. The facies geometries are produced by phases of fluvial erosion and subsequent fluvial deposition, caused by lake-level fluctuations in Palaeolake Olduvai, whose transgressions, taking place during continued subsidence, provided the accommodation space necessary for the fluvial deposition. The relatively good sorting of the sands most probably reflects derivation from windblown volcanically sourced sand in the river catchments.

Lemuta claystone unit (3) It comprises a massive olive waxy claystone, with no evidence of emersion, such as rootlet/burrowed units or desiccation cracks formed during lake withdrawal. Instead, the top of the claystone is heavily incised by the most fundamental incisional surfaces in the entire stratigraphic profile revealed by the archaeological excavations at HWK EE. Palaeolake Olduvai had returned to cover the Junction Area more permanently during this sedimentary interval, and dominated with clay sedimentation. A major withdrawal of Palaeolake Olduvai, prior to the deposition of LAS, eroded through any subsequent sedimentary sequence at HWK EE down as far as the middle of the higher claystone as revealed in Trenches T27, T28, and T29. A major time gap is represented by the incisional surface underlying the LAS. At this time, Palaeolake Olduvai would have been more restricted and therefore remote from the Junction Area. Major fluvial downcutting resulted. Only when the lake expanded later, would accommodation space have been provided within the incised topography to allow for resumed deposition.

Lower Augitic Sandstone unit (4) Renewed deposition is represented by LAS, which achieves a thickness of $2 \mathrm{~m}$ as reflected by the units exposed in the backwall of T1-Main Trench. Included are very augitic black sandstones, some planar or trough cross-bedded, less augitic 
grey facies, incorporating more feldspar grains, and gravelly sandstones or conglomeratic facies bearing clasts up to boulder size. At least three lake-parasequences are represented within LAS, of which only the lowermost does not have gravelly sediment at its base. The tapping of a new volcanic source is reflected by the highly augitic sands incorporated into unit (4). Major falls of Palaeolake Olduvai initiated phases of erosion and only partial transgressions of the lake, which did not reach the HWK EE area, resulting in the provision of accommodation space in which fluvial conglomerates or gravelly sands could be deposited, followed by very coarse to medium fluvial sand deposition.

Tuff IIB interval (5) It is represented by reddish sediments, involving $<30 \mathrm{~cm}$ accumulations of diamictite, interleaved with thin red claystone layers. These sedimentary cycles are incised and then overlain by a new phase of augitic fluvial gravels and sands. Both sedimentary phases are affected by major and minor phases of loading and water escape, with large flame structures of up to $2 \mathrm{~m}$ in dimension, particularly well developed in the Northeast part of the Trench T1 backwall (Fig. 4). The thin claystone layers of Tuff IIB are the first register of the return of Palaeolake Olduvai to the HWK EE area subsequent to Lemuta Member deposition. The associated thick diamictite units were deposited by mudflows, probably from the same volcano that sourced the augitic sands. The dramatic fluctuations of sedimentary style probably reflect palaeoclimatic shifts. The augitic gravels and sandstones represent wetter pluvial phases, whereas the mudflow diamictites were deposited under the more arid climatic conditions of interpluves.

The topography of the top of the LBII waxy claystones decreases around one meter from T1Main Trench (1407.3 $\mathrm{m}$ a.s.I.) to T29 $(1406.2 \mathrm{~m})$, and so it can be inferred that a $\mathrm{S}$ to NW incision gradient operated during Lemuta deposition and/or during earlier erosion of LBII deposits. Deposition in the LAS Member and the Tuff IIB zone is essentially fluvial (from silty sands to coarse sandstones). A gradient decreasing to the northwest can also be inferred for LAS deposition, this time supported by a refit line between conjoining lithics between T1Main Trench and T28 (Fig. 21d). While the top of the LBII waxy claystones is archaeologically sterile, materials are abundant throughout the Lemuta and LAS across all four trenches excavated at HKW EE. The Tuff IIB zone is exposed only in T1-Main Trench, where some archaeological material is recorded, although in much lower densities than in the underlying deposits. Interestingly, this substantial density change follows the largest archaeological gap observed in the sequence (see Fig. 6 and SOM S2), and thus it can be related to either the rapid depositional dynamics of the mudflows recorded within the interval, and/or a decrease of hominin presence in the area during Tuff IIB times. The latter explanation would be supported by the higher aridity interpreted for that interval.

The richness of HWK EE assemblages in both the Lemuta and LAS intervals is remarkable in terms of both lateral extension (similar densities from T1-Main Trench to T29) and vertical range (over two $\mathrm{m}$ of archaeological sediments). The best example of lateral continuity across the HWK EE deposits is the refit set between T28 and T1-Main Trench, which proves contextual connection between LAS materials $18 \mathrm{~m}$ apart (Fig. 21b). In addition, similar trench densities across an area of $300 \mathrm{~m}^{2}$ (northwest from T29 to southeast in T1-Main Trench) suggest that the space not sampled in our excavations also contains significant 
amounts of materials. Estimation of artefact and bone density in the study area during Lower/ Middle Bed II times (Fig. 39a) and predictive modelling of materials still preserved (i.e. spared from modern erosion: Fig. 39b), suggest that the archaeological concentration is substantial (see estimates in SOM S28).

Given the existence of a major erosional time-gap (i.e., the base of LAS) in the middle of the sampled stratigraphic interval, the continuous abundance of archaeological material in the vertical dimension for over two $\mathrm{m}$ of thickness is also challenging to interpret. Field observations, cross-sections (Fig. 6 and SOM S2) and geostatistics (Fig. 7) suggest that some archaeologically-sterile gaps exist between vertical clusters of materials, and therefore separate archaeological units can be distinguished. Such archaeological units generally represent different depositional events that are time-separated. However, both the geometry of archaeological units (Fig. 6) and the presence of inter-level refits (Figs. 21f-g) indicate that admixture of materials between archaeological units took place. Likewise, clusters of materials that were singled out as individual archaeological units may include more than one depositional event, which in parts of the excavation area can be vertically separated, but are jumbled in other sectors (see, for example, Fig. 15e). All this attests to the palimpsest nature of deposits and the existence of consecutive aggregation processes that took place across the HWK EE locality, as discussed in the next section.

\section{Site formation processes}

Accumulation processes in HWK EE involved both abiotic and biotic agents. The large amount of stone tool debris (nearly 13,000 artefacts $<20 \mathrm{~mm}$, see Table 10) suggests that stone-working activities took place in or near the HWK EE excavated trenches, which involved core knapping (de la Torre and Mora, submitted) and pounding (Arroyo and de la Torre, submitted). Likewise, the action of humans, mammalian carnivores and crocodiles is well attested over the highly dense bone assemblage (nearly 30,000 fragments; see Table 3), and therefore the role of biotic agents in the formation of the site is undeniable (Pante et al., submitted). Nonetheless, several proxies indicate that the impact of abiotic accumulators may have also been relevant. First, the co-occurrence of unmodified lithic and stone tool densities throughout the stratigraphic sequence and across trenches (Figs. 28 and 29) could be indicative of flow processes that captured natural and archaeological materials elsewhere, and then accumulated them together at HWK EE. In LAS, unmodified materials are often cobbles that appear spatially associated with artefacts and fossils. While in other sites such as EF-HR, conglomeratic deposits clearly indicate a fluvial origin for large clasts (see de la Torre et al., submitted), this is not the case at HWK EE, where grain size features are not as clear in explaining the accumulation process. The LAS deposits are generally coarse sandstones (Fig. 4), but granulometry highlights their fine matrix component (Figs. 5e-g), and large objects (including natural and unmodified lithics, and fossils) often appear clustered, rather than forming an evenly spread conglomerate (Fig. 26), within sediments that are otherwise silt-dominated. Spatial analysis (Figs. 37 and 38; SOM S19-S22) confirms clustering of distributions in most archaeological units (nearly all of them in LAS), with the possible exception of L10 (precisely in Lemuta). In this lower stratigraphic interval, unmodified materials are dominated by feldspar pebbles (rather than lava cobbles as in 
LAS), which are also embedded in a fine-grain matrix, and which also co-vary with archaeological materials. Thus, comparing density and size of the odd natural clast (in otherwise fine-grained sediments) with stone tools and fossils, leads us to conclude that covariation of these groups must share an abiotic source, most probably fluvial.

Artefact and fossil post-depositional modification also help in assessing the extent of fluvial action. The overall low incidence of heavily rounded fossils suggests that assemblages originated at or near the site. This is also supported by the size distribution of long bone midshaft specimens presented in Pante et al. (submitted), which shows an abundance of small specimens that are more likely to be transported in fluvial environments (Pante and Blumenschine, 2010). Nearly $80 \%$ of HWK EE lithic artefacts are fresh, and less than $5 \%$ present medium or severe rounding (Fig. 30a), which therefore suggests that the assemblage did not undergo substantial post-depositional transport. Nevertheless, larger (and heavier) artefacts show higher frequencies of fresh edges than smaller pieces (Figs. 30f-g), which could be related to longer transport distance for flakes than for cores, although potentially it might also be due to less resistant flake edges. In this line, it is unsurprising that chert presents the highest proportion of abraded pieces, as it is the raw material most sensitive to post-depositional damage when compared to lava and metamorphic stone tool edges. Interestingly, higher frequencies of chert lithics are in the slightly rounded category only, while all raw materials show similar indices of medium and abraded pieces; this is interpreted as the result of chert being more prone to rounding, rather than corresponding to a separate formation history, as proposed for EF-HR (de la Torre and Wehr, submitted).

Overall, stone artefact edge abrasion (Table 15) presents clear patterns, with a predominance of fresher materials in claystone contexts than in sandstone, and in Lemuta when compared to LAS (Figs 30c-d). It thus seems plausible to propose that, generally, the Lemuta assemblage is in a more pristine condition than LAS, due to a higher energy fluviatile context prevailing in the upper member. Stone tool size distribution shows a decreasing curve (Fig. 31b), with absolute predominance of small debris, followed by artefacts ranging from 20 to $39 \mathrm{~mm}$ in length, and substantially (and progressively) lower frequencies of bigger stone tools. This pattern suggests preservation of nearly all elements of core flaking chaîne opératoires, where prevalence of knapping debris is followed by flakes -which in HWK EE normally fall within the 20-39 mm range (see de la Torre and Mora, submitted)-, and then cores (represented by the peak of $>50$ g artefacts in Fig. 31a). While HWK EE size patterns are consistent with those proposed for unsorted assemblages (e.g. Schick, 1984; Petraglia and Potts, 1994), length distributions show features suggestive of some postdepositional bias, which are in close agreement with abrasion indices discussed above. Despite the large number of $<20 \mathrm{~mm}$ debris in LAS, relative frequencies are proportionally lower than in Lemuta (Fig. 31d), and statistically significant differences are observed between claystone and sandstone lithofacies. In fact, the overwhelming prevalence of $<20$ $\mathrm{mm}$ debris within the HWK EE assemblage as a whole is still below expectations from Olduvai experimental replications (de la Torre et al., 2017), and may indicate that part of the smaller sized debris was washed away from the site. 
Bone and artefact orientations are not strongly patterned, and plurimodal distributions generally prevail. Nevertheless, clear main modes are observed in some specific archaeological units (see Fig. 33), and there are strong similarities in the modes per trench and interval (Fig. 35): in Lemuta, materials from T28 and the north sector of T1-Main Trench are predominantly oriented NE-SW, whilst T27 and the south sector of T1-Main Trench share a NW-SE pattern. These opposing directions are particularly intriguing given the location of the trenches, for it results in a crossover of the two modes (see Fig. 35c). Even more interestingly (but equally difficult to interpret), similarities between the modes of T1Main Trench north sector and T28 remain strong (although now with a NNE-SSW direction), while T27 and T28 share in LAS an E-W primary mode. Complexity of these orientation patterns does not help to firmly establish a clear flow direction or channel architecture, although Lemuta (T1-Main Trench Areas 1 and 2 secondary modes; T27 primary mode) and LAS (T1-Main Trench Area 2 primary mode; T27 and T28 secondary modes) patterns generally follow a SE-NW trend similar to the S- NW downward topography discussed earlier.

Refit lines are also inconclusive as far as orientation patterns are concerned; the statistical comparison of refit set orientations and fossil and artefact rose diagrams and modes suggests that both samples could be drawn from the same population. However, results do not convincingly define such similarities (SOM S26), and there are no clear patterns in the visual comparison of orientations (SOM S27). In any case, the extremely low return of refits (Table 7) cannot only be attributed to the analytical difficulties of Olduvai raw materials (Proffitt and de la Torre, 2014), and the paucity of conjoining sets in both lithic and bone assemblages, despite the substantial time invested, might potentially be linked to depletion of elements by post-depositional processes.

When all taphonomic proxies are considered, the resulting picture of site formation processes at HWK EE is intriguing; on the one hand, the sedimentary matrix in most units does not suggest high-energy flows, stone tools and fossils are mostly fresh, frequencies of small items are significantly high, and orientation patterns are mostly plurimodal. Fabrics of archaeological material are mostly planar (Fig. 36), orbiting around the area considered by Lenoble and Bertran (2004) as typical of undisturbed sites. On the other hand, unmodified material, although in matrix-supported sediments, covaries with fossils and stone tools; refit lines conjoin fossils and artefacts separated by substantial vertical distances, raw materials more sensitive to edge damage (e.g., chert) indicate sediment abrasion, and frequencies of debris, despite their large numbers, are still proportionally lower than in experimental assemblages.

All of this indicates that fluvial action was involved in HWK EE assemblage formation. The role of water flow was less pronounced in Lemuta than in LAS, although occasional (but pervasive) feldspar pebbles indicate some traction in Lemuta as well, and Lemuta sands are certainly fluvial. Sediment source changed in LAS, and higher energy flows deposited sand with local clusters of large clasts that include unmodified and archaeological material. Some archaeological units are largely undisturbed (e.g., L10, T27L32) while others suggest more significant post-depositional disturbance (e.g., L4, L6-LCHA), but most seem to represent a 
middle ground where biotic agents were the main accumulators, and where water may have contributed elements (particularly unmodified lithic clasts) and removed others (e.g., part of the $<20 \mathrm{~mm}$ lithic fraction).

Overall, hominins and carnivores significantly contributed to the formation of the HWK EE site, which may also include natural background bone assemblages (e.g., L8). Still, the huge accumulation of archaeological material at HWK EE, with a collected sample of nearly 30,000 fossils and 18,000 lithic artefacts (Table 3), and an inferred sample that triples this amount (e.g., $\sim 43,000$ stone tools more in LAS and $\sim 30,000$ in Lemuta: see details in SOM S28) cannot be attributed only to biotic agents, and the role of abiotic agents, in the form of runoff, may have also been significant.

\section{The palaeoecological setting of HWK EE}

The prevalence of sandstone units indicates the existence of a river that eroded through and interlayered with claystones in an area relatively close to the edge of Palaeolake Olduvai. In the lower Lemuta sandstone samples, the identification of palm phytoliths (mainly in western trenches T29 and T28) suggests local fresh water availability from rivers or marshy wetland, which is also indicated by clay geochemistry in the HWK E area (Deocampo et al., 2002). The identification of phytoliths from the $C_{4}$ grass group, associated with $C_{3}$ grasses and palms, describes a vegetated landscape with a mix of trees and grasses from the $C_{3}$ group and open areas with $\mathrm{C}_{4}$ grasses where grazers such as Equus could feed (Rivals et al., submitted). These conditions represent a medium to high temperature environment with moist soils. Bulliform cells could also attest to local wet areas with dry conditions where high transpiration rates occur (Bremond et al., 2005).

In the upper samples from Lemuta sandstones, phytoliths were not abundant and the few phytoliths identified correspond mostly to grasses with a scarce palm presence. Conversely, the diatom results for sample \#84 (T1-Main Trench) suggest that the accumulation occurred in the littoral zone of a river or a freshwater wetland highly vegetated with moderate water flow. The diatoms recovered from this sample are dominated by N. amphibia (Fig. 24 and Table 8), a species also prevalent at DK, suggesting a similar freshwater environment (Albert et al., 2015). However, sample \#84 was co-dominated by some Fragilariales algae such as Pseudostaurosira and Staurosirella, which are common in unstable environments. Low phytolith abundance recorded in olive waxy claystone units probably reflect the low preservation potential of siliceous material in the saline-alkaline lake waters in which this facies was deposited.

The lowest samples of LAS from T1-Main Trench (grey coarse sandstone) display higher phytolith abundances with the presence of grasses, probably from the $C_{3}$ subfamily and trees. These results are consistent with the diet observed for the antilopin and the alcelaphin, with an increase in leaf browsing for this period (Rivals et al., submitted). Palms were not common in this part of the stratigraphy.

The faunal assemblage from HWK EE (Table 14) is both large and well preserved, allowing for detailed reconstructions of the palaeoecology of the site. As discussed elsewhere (Prassack et al., submitted), the HWK EE avifauna is abundant and diverse, and reflects a 
lake shore or wetland environment which, due to the presence of perching and treeroosting taxa, attest to suitable roosting trees nearby. Bovid composition supports the presence of extensive grasslands during these times, while the fish data also support the presence of strong seasonality (Bibi et al., submitted). Tooth wear analysis (Rivals et al., submitted) detected differences in the dietary traits of ungulates between Lemuta and LAS. These differences may correspond to changes in resource partitioning among species, or to seasonal differences in the period of death of these animals in each stratigraphic interval (Rivals et al., submitted). Stable isotope data from HWK EE fossil teeth (Uno et al., submitted) indicate abundant $\mathrm{C}_{4}$ vegetation and arid conditions (with median value of +0.3 $\%$ ), which is $1.7 \%$ more depleted than the median value from modern fauna in Tanzania today (Van der Merwe, 2013).

The general account provided here suggests an open habitat with a permanent water source and trees. Facies evidence suggests that the LAS was deposited by rivers under a more humid climatic setting, which were likely perennial or semi-perennial. It is likely that there was considerable competition at the site for carcass food resources and there was probably a high risk of predation from both mammalian carnivores and crocodiles. The latter were particularly abundant during LAS times, as evidenced by the number of crocodile teeth recovered (see above), and some crocodile tooth-marked mammal bones (Pante et al., submitted). Despite these challenges, hominins utilized the site over multiple intervals, suggesting the affordances offered by the site outweighed the risks.

\section{HWK EE in the context of the Olduvai Bed I-II sequence}

Considering materials from our excavations only, the HWK EE stone tool assemblage would be one of the largest and densest at Olduvai Gorge, with over 18,000 artefacts and $450 \mathrm{~kg}$ of worked stone. However, the HWK EE assemblage is in fact much bigger, because the Leakey collection includes nearly 3,000 artefacts that weigh a total of $230 \mathrm{~kg}$ (Pante and de la Torre, submitted), and our density calculations in the present paper predict an even larger size for the site (see Fig. 39). HWK EE thus becomes one of the largest (if not the largest) Oldowan assemblages from Olduvai Beds I and II and elsewhere in East Africa, and offers valuable data to characterize the technology of pre-Acheulean hominins (see de la Torre and Mora, submitted).

The large quantity of stone tools at HWK EE might certainly be connected, at least in part, to water action that could have contributed to the archaeological accumulation. It is important to note that the site of HWK E (Leakey, 1971), which contains another major lithic assemblage in a very similar stratigraphic position within the LAS interval (Fig. 2), is located nearby (Fig. 1). Therefore, it could be proposed that fluvial rearrangement of assemblages operated in this southern part of the Junction Area during LAS, forming one of the most archaeologically productive zones of Olduvai Gorge. On the other hand, the density of materials in the Lemuta interval at HWK EE is similar to LAS, but post-depositional disturbance is not as apparent and therefore does not alone explain the large accumulation. Additionally, HWK EE frequencies of small artefacts do not place this assemblage among the most disturbed of Olduvai Beds I and II; debris deficit does not occur only at HWK EE, but elsewhere among the Olduvai sites (de la Torre et al., 2017). Actually, HWK EE yielded far 
greater frequencies of small artefacts than any of the classic Olduvai assemblages excavated by Leakey (1971). Classic sites such as FLK Zinj and TK, which are among those with the lowest inferred post-depositional disturbance according to size sorting studies (Petraglia and Potts, 1994; de la Torre et al., 2017), present proportions of debris $\sim 50 \%$ (de la Torre et al., 2017), considerably lower than the $>80 \%$ average presented for HWK EE in this paper. Certainly, more limited recovery techniques during Leakey's excavations should be factored in when explaining such discrepancies (see discussion in de la Torre et al., 2017). Nevertheless, no size distribution data have yet been made available from new excavations on these and other iconic sites (e.g. Santonja et al., 2014; Sanchez-Yustos et al., 2016), where recovery methods are expected to be more comprehensive, and which could help to clarify the reliability of Leakey's collections length distributions. Nonetheless, the pervasive and overwhelming predominance of debris at HWK EE should serve as a note of caution against invoking abiotic agents as the only factor explaining the large size of this assemblage when compared to other Olduvai Beds I and II sites that, as a matter of fact, seem to yield far lower frequencies of runoff-sensitive elements.

The HWK EE bone assemblage is also remarkably large and well preserved, in particular when compared to other Middle and Upper Bed II sites (Monahan, 1996), which are normally much smaller and more poorly preserved than Bed I and LBII assemblages (Bunn, 1982; Blumenschine, 1991; Dominguez-Rodrigo et al., 2007). Some of the HWK EE bones (e.g. most of the L8 assemblage) could correspond to background deposits, which have been well attested to at Olduvai (Leakey, 1971; Binford, 1987; Blumenschine and Masao, 1991; de la Torre and Mora, 2005; Dominguez-Rodrigo et al., 2007). Water action over Olduvai Bed I and II bone assemblages has been suggested for most sites (Benito-Calvo and de la Torre, 2011; de la Torre and Benito-Calvo, 2013), and probably contributed to the formation of the HWK EE bone assemblage. Nonetheless, biotic agents are usually considered the main actors in the formation of Olduvai sites, be it mammalian carnivores alone (e.g. DominguezRodrigo et al., 2007), crocodiles (Njau and Blumenschine, 2012), or scenarios where hominin and carnivore hunting/scavenging activities interplayed (e.g. Bunn, 1982; Blumenschine, 1991). Hominins during the Lemuta interval at HWK EE appear to have regularly obtained large animals that weighed between 100 and $900 \mathrm{~kg}$ through scavenging, whereas LAS fossils may show earlier access to flesh from animals of this size, as suggested by the lower overall mammalian carnivore signal (Pante et al., submitted). However, these variances could also be the result of seasonal differences between the time periods of accumulation of these two intervals (see Pante et al., submitted; Rivals et al., submitted). Interestingly, the crocodile presence is more visible in LAS, which therefore suggests that trophic pressure was not necessarily lower in LAS, and reminds us of the ecological risks posed to Olduvai hominins (Blumenschine and Peters, 1998; Njau and Blumenschine, 2012).

In palaeoecological terms, the HWK EE diatom composition is similar to that reported from the Junction Area (Liutkus and Ashley, 2003; Ashley et al., 2009), but dominant taxa are different, and indicate a littoral zone of a freshwater ecosystem around HWK EE. Previous vegetation studies of LBII from HWK EE indicated a humid environment with wetlands where palms would dominate. Later, an increase in dry conditions is reflected in a reduction in palms and an increase of grasses (Albert et al., 2006; Bamford et al., 2006), that would 
continue to Middle Bed II times, where palms would still be present associated with humid environments, although in lower abundance. As discussed by Bibi et al. (submitted), the HWK EE bovid composition (and other Middle Bed II assemblages) is very different from that in Middle Bed I, which has a higher proportion of wet-habitat taxa (Reduncini). The HWK Complex during Lowermost Bed II (LMBII) times, especially during post-incision, is also rich in fossil birds and exhibits a similar community profile to our excavated assemblage at HWK EE (Prassack et al., submitted), but with a greater dominance of cormorants (Prassack, 2014). Thus, the HWK EE bird assemblage was deposited in a more open and heterogeneous, but still wet, landscape compared to LMBIl times (Prassack et al., submitted). Overall, however, conditions were arid -oxygen isotope median value of $+0.3 \%$ (Uno et al., submitted)-, but generally similar to the present-day Serengeti (Bibi et al., submitted).

\section{Conclusions}

This paper has reported outcomes of OGAP investigations at the HWK EE outcrop. The datarich approach adopted in the description of the archaeo-stratigraphic sequence has fulfilled three main objectives. The first objective was to produce a full account of field and analytical results of our excavations, and thus avoid interpretations based on only a partial and/or preliminary study of assemblages. By including raw data on the individual archaeological units and their context, the format of this paper also seeks to make available the tools necessary for assemblage comparisons within Olduvai and elsewhere. Second, detailed accounts of the archaeological and palaeoenvironmental context of excavations was deemed essential to assess site formation processes, which in turn constitute the basis for the interpretation of technological (de la Torre and Mora, submitted) and subsistence behaviours of hominins, carnivores (Pante et al., this volume) and herbivores (Rivals et al., submitted) throughout the HWK EE sequence. Last, the present paper also serves as the foundation for several other studies on Middle-Upper Bed II palaeoecology (Bibi et al., submitted; Prassack et al., submitted; Uno et al., submitted) and raw material availability (McHenry and de la Torre, submitted), where the HWK EE record is the primary reference.

OGAP excavations at HWK EE have unearthed a substantial fossil and artefact assemblage, one of the largest within the Olduvai sequence as a whole, and probably the most extensive for the period $\sim 1.7 \mathrm{Ma}$. The size of the assemblage, its excellent preservation and the wealth of archaeological and palaeoenvironmental proxies should make of HWK EE a point of reference for research in a crucial time interval. Our study indicates the presence of a river in an area near the edge of Palaeolake Olduvai. Freshwater from river and/or marshy wetlands supplied a vegetated landscape with trees and $C_{3}$ grasses, but also with nearby open areas of $\mathrm{C}_{4}$ grasses. The archaeological assemblage spans three main stratigraphic intervals in the contact between Lower to Middle Bed II, and includes several overlaying assemblages that can be laterally identified across the four trenches excavated at HWK EE. Intensive biotic activity in the area is evidenced by the large fossil assemblage preserved at the site, which contains fish, abundant birds, crocodiles and macro-mammals. Both hominins and carnivores contributed to the formation of the assemblage, although 
differences are observed per stratigraphic interval, with a more intense hominin scavenging signature in the Lemuta than in the LAS assemblage. Our spatial and taphonomic study suggests that abiotic agents also contributed to the formation of the assemblage, mostly in the form of run-off water that rearranged and jumbled separated occupational events into a number of superimposed archaeological palimpsests. Placed at the boundary between Lower and Middle Bed II, and lacking handaxes, the HWK EE core-and-flake assemblage constitutes one of the last examples of the Oldowan at Olduvai, and enables the portrayal of a detailed picture of the technological and subsistence strategies of early Homo before the advent of the Acheulean.

\section{Acknowledgements}

We are grateful for the contributions of A. Benito-Calvo (granulometry), R. Peters (conservation), A. Venance (bone refits), F. Bibi (bone refits and bovids), K. Prassack (birds), K. Steward (fish), K. Uno (isotopes), F. Rivals (tooth wear), Goodluck Peters (trench supervision), C. Martin Ramos (finds processing supervision), and members of the OGAP field team. Editorial guidance by Sarah Elton is gratefully acknowledged. Fieldwork at HWK EE by OGAP was authorized by the Commission for Science and Technology (COSTECH) and the Department of Antiquities, Tanzania. Financial support for fieldwork was gratefully received from PAST (Palaeontological Scientific Trust, South Africa) for IGS, from the German Science Foundation (DFG grant STO 275/9-1) to HS, Pontificia Universidad Javeriana (IDPPTA 6676) to CARR, and from the Spanish Ministry of Economy and Competiveness to RMA (HAR2013-42054-P) and to ARC (BES-2014-067985). Funding by the NSF (BCS-0852292 to LM), British Academy (IP090186 to IdIT, 121630 to Idlt/MCP), the Wenner-Gren Foundation (Gr. 9245 to MCP) and the European Research Council-Starting Grants (283366 to IdIT), is gratefully acknowledged. 


\section{References}

Akaike, H., 1973. Information theory and an extension of the maximum likelihood principle. In: Petrov, B.N., Csáki, F. (Eds.), 2nd International Symposium on Information Theory, Tsahkadsor, Armenia, USSR, September 2-8, 1971. Akadémiai Kiadó, Budapest, pp. 267281.

Akaike, H., 1974, A new look at the statistical model identification. IEEE Transactions on Automatic Control 19, 716-723.

Albert, R.M., Weiner, S., 2001. Study of phytoliths in prehistoric ash layers using a quantitative approach. In: Meunier, J.D., Coline, F. (Eds.), Phytoliths: Applications in Earth Sciences and Human History. A.A. Balkema Publishers, Lisse, pp. 251-266.

Albert, R.M., Bamford, M.K., Cabanes, D., 2006. Palaeoecological significance of palms at Olduvai Gorge, Tanzania, based on phytolith remains. Quatern. Intern. 193, 41-48.

Albert, R.M., Bamford, M.K., Stanistreet, I., Stollhofen, H., Rivera-Rondón, C., RodríguezCintas, A., 2015. Vegetation landscape at DK locality, Olduvai Gorge, Tanzania. Palaeogeogr. Palaeoclimatol. Palaeoecol. 426, 34-45.

Arroyo, A.,de la Torre, I., (submitted). Pounding tools in HWK EE and EF-HR (Olduvai Gorge, Tanzania): percussive activities in the Oldowan - Acheulean transition. J. Hum. Evol.

Ashley, G.M., Tactikos, J.C., Owen, R.B., 2009. Hominin use of springs and wetlands: Paleoclimate and archaeological records from Olduvai Gorge ( 1.79-1.74 Ma). Palaeogeogr. Palaeoclimatol. Palaeoecol. 272, 1-16.

Bamford, M.K., Albert, R.M., Cabanes, D., 2006. Plio-Pleistocene macroplant fossil remains and phytoliths from Lowermost Bed II in the eastern palaeolake of Olduvai Gorge, Tanzania. Quatern. Int. 193, 95-112.

Behrensmeyer, A.K., 1978. Taphonomic and ecologic information from bone weathering. Paleobiology 4, 150162.

Benito-Calvo, A., de la Torre, I., 2011. Analysis of orientation patterns in Olduvai Bed I assemblages using GIS techniques: Implications for site formation processes. J. Hum. Evol. 61, 50-60.

Benito-Calvo, A., Martínez-Moreno, J., Jordá Pardo, J. F., de la Torre, I., Torcal, R.M., 2009. Sedimentological and archaeological fabrics in Palaeolithic levels of the South-Eastern Pyrenees: Cova Gran and Roca dels Bous Sites Lleida, Spain. J. Archaeol. Sci. 36, 25662577.

Benn, D., 1994. Fabric shape and the interpretation of sedimentary fabric data. J. Sediment. Res. A644, 910-915.

Bertran, P., Lenoble, A., 2002. Fabriques des niveaux archéologiques: Méthode et premier bilan des apports à l'etude taphonomique des sites paléolithiques. Paléo 14, 13-28. 
Bertran, P., Claud, É., Detrain, L., Lenoble, A., Masson, B., Vallin, L., 2006. Composition granulométrique des assemblages lithiques, application à l'étude taphonomique des sites paléolithiques. Paléo 18, 7-36.

Bibi, F., Pante, M., Souron, A., Stewart, K., Varela, S., Werdelin, L., Boisserie, J.-R., Fortelius, M., Hlusko, L., Njau, J., de la Torre, I.(submitted). Mammals and Fish from the OldowanAcheulean Transition at Olduvai Gorge, Tanzania, and the Paleoecology of the Serengeti J. Hum. Evol.

Binford, L.R., 1987. Searching for camps and missing the evidence?: another look at the Lower Paleolithic. In: Soffer, O. (Ed.), The Pleistocene Old World: Regional Perspectives. Plenum Press, New York, pp. 17-31.

Blumenschine, R.J., 1991. Hominid carnivory and foraging strategies, and the socioeconomic function of early archaeological sites. Phil. Trans. R. Soc. B, 334, 211-221.

Blumenschine, R. J., Masao, F.T., 1991. Living sites at Olduvai Gorge, Tanzania? Preliminary landscape archaeology results in the basal Bed II lake margin zone. J. Hum. Evol. 21, 451462.

Blumenschine, R.J., Marean, C.W., Capaldo, S.D., 1996. Blind tests of interanalyst correspondence and accuracy in the identification of cut marks, percussion marks, and carnivore tooth marks on bone surfaces. J. Archaeol. Sci. J. Archaeol. Sci. 23, 493-507.

Blumenschine, R.J., Peters, C.R., 1998. Archaeological predictions for hominid land use in the paleo-Olduvai Basin, Tanzania, during lowermost Bed II times. J. Hum. Evol. 34, 565-607.

Bremond, L., Alexandre, A., Pyeron, O., Guiot, J., 2005. Grass water stress estimated from phytoliths in West Africa. J. Biogeogr. 32, 311-327

Bullock, P., Fedoroff, N., Jongerius, A., Stoops, G., Tursina, T., 1985. Handbook for Soil Thin Section Description, Waine Research Publications, Wolverhampton, 152.

Bunn, H.T., 1982. Meat-Eating and Human Evolution: Studies on the Diet and Subsistence Patterns of Plio-Pleistocene Hominids in East Africa. Ph.D. Dissertation, University of California, Berkeley.

Caljon, A.G., 1991. Sedimentary diatom assemblages in the northern part of Lake Tanganyika. Hydrobiologia 226, 179-191.

Conolly, J., Lake, M., 2006. Geographical Information Systems in Archaeology. Cambridge University Press, Cambridge.

Courty, M. A., 2001, Microfacies analysis assisting archaeological stratigraphy, In: Goldberg, P., Holliday, V.T., Ferring, C.R., (Eds.), Earth Sciences and Archaeology. Kluwer, New York, pp. 205-239.

Courty, M.A., Goldberg, P., Macphail, R.I., 1989. Soils and Micromorphology in Archaeology (1st Edition). Cambridge University Press, Cambridge.

Curray, J.R., 1956. The analysis of two-dimensional orientation data. J. Geol. 64, 117-134. 
de la Torre, I., Albert, R.M., Macphail, R., McHenry, L., Pante, M., Rodríguez-Cintas, A., Stanistreet, I., Stollhofen, H.(submitted). The contexts and early Acheulean archaeology of the EF-HR landscape (Olduvai Gorge, Tanzania). J. Hum. Evol.

de la Torre, I., Arroyo, A., Proffitt, T., Martín-Ramos, C., Theodoropoulou, A., 2015. Archaeological fieldwork techniques in Stone Age sites. Some case studies. In: Roda, X., Mora, R. (Eds.), Métodos y técnicas para la recuperación del registro arqueológico: una mirada desde el presente. Treballs d'Arqueologia, 20, Barcelona, pp. 21-40.

de la Torre, I., Benito-Calvo, A., 2013. Application of GIS methods to retrieve orientation patterns from imagery; a case study from Beds I and II, Olduvai Gorge (Tanzania). J. Archaeol. Sci. 40, 2446-2457.

de la Torre, I., Benito-Calvo, A., Proffitt, T., (2017). The impact of hydraulic processes in Olduvai Beds I and II, Tanzania, through a particle dimension analysis of stone tool assemblages. Geoarchaeology, XXX.

de la Torre, I., Mora, R., 2005. Unmodified lithic material at Olduvai Bed I: Manuports or ecofacts? J. Archaeol. Sci. J. Archaeol. Sci. 32,273-285.

de la Torre, I., Mora, R. (submitted). Oldowan technological behaviour at Olduvai Gorge, Tanzania: The HWK EE stone tool assemblage. J. Hum. Evol.

de la Torre, I., and Wehr, K. (submitted). Site formation processes of the early Acheulean assemblage at EF-HR (Olduvai Gorge, Tanzania). J. Hum. Evol.

Daniel, W.W., 1990. Kolmogorov-Smirnov one-sample test. Applied Nonparametric Statistics 2nd ed. PWS-Kent, Boston.

Deocampo, D.M., Blumenschine, R.J., Ashley, G.M., 2002. Wetland diagenesis and traces of early hominids, Olduvai Gorge, Tanzania. Quatern. Res. 57, 271-281.

Domínguez-Rodrigo, M., Barba, R., Egeland, C.P., 2007. Deconstructing Olduvai. A Taphonomic Study of the Bed I Sites. Springer, Dordrecht.

Fisher, R., 1925. Statistical Methods for Research Workers. Oliver and Boyd, Edinburgh.

Folk, R.L., 1959. Practical petrographic classification of limestones: American Association of Petroleum Geologists Bulletin 43, 1-38.

Gasse, F., 1980. Les diatomées lacustres Plio-Pleistocènes du Gadeb

(Ethiopie).Systématique, paléoécologie, biostratigraphie. Revue Algologique. Mémoire hors-série

3, 1-360.

Gasse, F., 1986. East African Diatoms: Taxonomy, Ecological Distribution. Gebruder Borntraeger Verlagsbuchhandlung, Berlin.

Gasse, F., Juggins, S., Khelifa, L.B., 1995. Diatom-based transfer functions for inferring past hydrochemical characteristics of African lakes. Palaeogeogr. Palaeoclimatol. Palaeoecol. 117, 31-54. 
Gasse, F., Tekaia, F., 1983. Transfer functions for estimating paleoecological conditions (pH) from East African diatoms. Hydrobiologia 103, 85-90.

Gentry, A.W., Gentry, A., 1978. Fossil Bovidae (Mammalia) of Olduvai Gorge, Tanzania. Part I. Bulletin of the British Museum, Geological Series 29, 289-446.

Goldberg, P., Macphail, R.I., 2006. Practical and Theoretical Geoarchaeology, , Blackwell Publishing, Oxford.

Graham, D.J., Midgley, N.G., 2000. Graphical representation of particle shape using triangular diagrams: an Excel spreadsheet method. Earth Surf. Process. Landf. 25, 14731477.

Haining, R., 1990. The use of added variable plots in regression modelling with spatial data. The Professional Geographer 42, 336-345.

Hay, R.L., 1976. Geology of the Olduvai Gorge. University of California Press, Berkeley.

Ihaka, R., Gentleman, R., 1996. R: A language for data analysis and graphics. J. Comput. Graph. Stat., 5, 299-314.

Isaac, G.L., Harris, J.W.K., Kroll, E.M., 1997. The stone artefact assemblages: A comparative study. In: Isaac, G.L. (Ed.), Koobi Fora Research Project. Volume 5: Plio-Pleistocene Archaeology. Oxford University Press, Oxford, pp. 262-362.

Jenks, G.F., Caspall, F.C., 1971. Error in choropleth maps: definition, measurement, reduction. Annals of Association of American Geographers 61, 217-244.

Jorayev, G., Wehr, K., Benito-Calvo, A., Njau, J., de la Torre, I. 2016. Imaging and photogrammetry models of Olduvai Gorge (Tanzania) by unmanned aerial vehicles: A high-resolution digital database for research and conservation of Early Stone Age sites. J. Archaeol. Sci. 75, 40-56.

Katz, O., Cabanes, D., Weiner, S., Maeira, A.M., Boaretto, E., Shahack-Gross, R., 2010. Rapid phytolith extraction for analysis of phytolith concentrations and assemblages during an excavation: an application at Tell es-Safi/Gath, Israel. J. Archaeol. Sci. 37 , 1557-1563.

Kaufman, L., Rousseeuw, P.J., 1990. Finding Groups in Data: An Introduction to Cluster Analysis. Wiley and Sons, Hoboken, New Jersey.

Krammer, K., Lange-Bertalot, H., 1991. Bacillariophyceae. 3. Teil: Centrales, Fragilariaceae, Eunotiaceae. Gustav Fischer Verlag, Stuttgart.

Krammer, K., Lange-Bertalot, H., 2004. Bacillariophyceae 4. Teil: Achnanthaceae, Kritische Erganzungen zu Navicula (Lineolatae) und Gomphonema Gesamtliteraturverzeichnis Teil 1-4. Second revised edition with "Ergänzungen und Revisionen" by $\mathrm{H}$. Lange-Bertalot. Spektrum Akademischer Verlag Heidelberg, Berlin.

Kvamme, K.L., 1983. Computer processing techniques for regional modelling of archaeological site locations. Advances in Computer Archaeology 1, 26-52. 
Kvamme, K.L., 1988. Development and testing of quantitative models. In: Judge, W.J., Sebastian, L., (Eds.), Quantifying the Present and Predicting the Past: Theory, Method and Application of Archaeological Predictive Modelling. Bureau of Land Management, Washington DC, pp. 325-427.

Lange-Bertalot, H., 2001. Navicula sensu stricto, 10 Genera Separated from Navicula sensu stricto, Frustulia. A.R.G. Gantner Verlag K.G, Ruggell.

Leakey, L.S.B., 1951. Olduvai Gorge. A Report on the Evolution of the Hand-Axe Culture in Beds I-IV. Cambridge University Press, Cambridge.

Leakey, M.D., 1971. Olduvai Gorge. Vol 3. Excavations in Beds I and II, 1960-1963. Cambridge University Press, Cambridge.

Lenoble, A., Bertran, P., 2004. Fabric of Palaeolithic levels: methods and implications for site formation processes. J. Archaeol. Sci. 31, 457-469.

Levi Sala, I., 1986. Use wear and post-depositional surface modification: A word of caution. J. Archaeol. Sci. 13, 229-244.

Liutkus, C.M., Ashley, G.M., 2003. Facies model of a semiarid freshwater wetland, Olduvai Gorge, Tanzania. J. Sediment. Res. 73, 691-705.

Lund, U., Agostinelli, C. 2007. Package: "Circular" in R. Available at http://cran.rproject.org/web/packages/circular/index.html.

MacQueen, J., 1967. Some methods for classification and analysis of multivariate observations. Proceedings of the Fifth Berkeley Symposium on Mathematical Statistics and Probability 1, 281-297.

Macphail, R.I., Cruise, G.M., 2001. The soil micromorphologist as team player: a multianalytical approach to the study of European microstratigraphy. In: Goldberg, P., Holliday, V., Ferring, R., (Eds.), Earth Science and Archaeology. Kluwer Academic/Plenum Publishers, : New York, pp. 241-267.

McHenry, L.J., Njau, J.K., de la Rotte, I., Pante, M.C., 2016. Geochemical "fingerprints" for Olduvai Gorge Bed II tuffs and implications for the Oldowan-Acheulean transition. Quatern. Res. 85, 147-158.

McHenry, L., de la Torre, I. (submitted). Hominin raw material procurement in the OldowanAcheulean transition at Olduvai Gorge. J. Hum. Evol.

van der Merwe, N.J., 2013. Isotopic ecology of fossil fauna from Olduvai Gorge at ca 1.8 Ma, compared with modern fauna. S. Afr. J. Sci.109, 1-14.

Monahan, C.M., 1996. New zooarchaeological data from Bed II, Olduvai Gorge, Tanzania: implications for hominid behavior in the Early Pleistocene. J. Hum. Evol. 31, 93-128.

Mora, R., de al Torre, I., Martínez-Moreno, J., 2010. ArqueoUAB: A systematic archaeographic approach for the analysis of Palaeolithic sites. In: Melero, F.J., Cano, P., 
Revelles, J., (Eds.). Computer Applications and Quantitative Methods in Archaeology. CAA Fusion of Cultures, Granada. 1-3.

Murphy, C.P., 1986, Thin Section Preparation of Soils and Sediments. A B Academic Publishers, Berkhamsted.

Njau, J.K., Blumenschine, R.J., 2012. Crocodylian and mammalian carnivore feeding traces on hominid fossils from FLK 22 and FLK NN 3, Plio-Pleistocene, Olduvai Gorge, Tanzania. J. Hum. Evol. 63, 408-417.

Pante, M.C., Blumenschine, R.J., 2010. Fluvial transport of bovid long bones fragmented by the feeding activities of hominins and carnivores. J. Archaeol. Sci. 3, 846-854.

Pante, M., de la Torre, I. (submitted). A hidden treasure of the Lower Pleistocene: the Leakey HWK EE assemblage. J. Hum. Evol.

Pante, M. Njau, J.K., Hensley-Marschand, B., Keevil, T.L., Martín-Ramos, C., Peters, R.F., de la Torre, I. (submitted). The carnivorous feeding behavior of early Homo at HWK-EE, Bed II, Olduvai Gorge, Tanzania. J. Hum. Evol.

Pearson, K., 1900. On the criterion that a given system of deviations from the probable in the case of a correlated system of variables is such that it can be reasonably supposed to have arisen from random sampling. Philosophical Magazine Series 5. 50 302, 157-175.

Petraglia, M.D., Potts, R., 1994. Water flow and the formation of Early Pleistocene artifact sites in Olduvai Gorge, Tanzania. J. Anthropol. Archaeol. 13, 228-254.

Prassack, K.A., 2014. Landscape distribution and ecology of Plio-Pleistocene avifaunal communities from Lowermost Bed II, Olduvai Gorge, Tanzania. J. Hum. Evol. 70, 1-15.

Prassack, K., Pante, M.C., Njau, J.K., de la Torre, I. (submitted). The Paleoecology of Fossil Birds from Middle Bed II, at Olduvai Gorge, Tanzania J. Hum. Evol.

Proffitt, T. (submitted). Diachronic changes in Oldowan technology in Beds I and Lower Bed II. J. Hum. Evol.

Proffitt, T., de la Torre, I., 2014. The effect of raw material on inter-analyst variation and analyst accuracy for lithic analysis: a case study from Olduvai Gorge. J. Archaeol. Sci. 45, 270-283.

Renberg, I., 1990. A procedure for preparing large sets of diatom slides from sediment cores. J. Paleolimnol. 4, 87-90.

Ripley, B.D., 1976. The second order analysis of stationary point process. Journal of Applied Probability 13, 255-266.

Ripley, B.D., 1981. Spatial Statistics. Wiley and Sons, New York.

Rivals, F., Uno, K., Bibi, F., Pante, M., Njau, J.K., de la Torre, I. (submitted). Dietary traits of the ungulates from the HWK EE site at Olduvai Gorge (Tanzania): Diachronic changes and seasonality. J. Hum. Evol. 
Robert, C., Casella, G., 2004. Monte Carlo Statistical Methods. Springer-Verlag, New York.

Ryves, D.B., Battarbee, R.W., Fritz, S.C., 2009. The dilemma of disappearing diatoms: Incorporating diatom dissolution data into palaeoenvironmental modelling and reconstruction. Quatern. Sci. Rev. 28, 120-136.

Santonja, M., Panera, J., Rubio-Jara, S., Pérez-González, A., Uribelarrea, D., DomínguezRodrigo, M., Mabulla, A. Z. P., Bunn, H. T. \& Baquedano, E. 2014. Technological strategies and the economy of raw materials in the TK (Thiongo Korongo) lower occupation, Bed II, Olduvai Gorge, Tanzania. Quatern. Int. 322-323, 181-208.

Sánchez-Yustos, P., Diez-Martín, F., Domínguez-Rodrigo, M., Fraile, C., Duque, J., Uribelarrea, D., Mabulla, A.Z.P., Baquedano, E., 2016. Techno-economic human behavior in a context of recurrent megafaunal exploitation at 1.3 Ma. Evidence from BK4b (Upper Bed II, Olduvai Gorge, Tanzania). J. Archaeol. Sci.: Reports 9, 386-404.

Schick, K.D., 1984. Processes of Palaeolithic Site Formation: An Experimental Study. Ph.D. Dissertation, University of California, Berkeley.

Shapiro, S.S., Wilk, M.B., 1965. An analysis of variance test for normality complete samples. Biometrika 52 3-4, 591-611

Shea, J.J., 1999. Artifact abrasion, fluvial processes, and "Living Floors" from the Early Paleolithic site of 'Ubeidiya (Jordan Valley, Israel). Geoarchaeology 14, 191-207.

Shepard, F.P., 1954. Nomenclature based on sand-silt-clay ratios. J.Sediment. Petrol. 24, 151-158.

Sneed, E.D., Folk, R.L., 1958. Pebbles in the Lower Colorado River, Texas a atudy in particle morphogenesis. The Journal of Geology 66, 114-150.

Stanistreet, I.G. (2012). Fine resolution of early hominin time, Beds I \& II, Olduvai Gorge, Tanzania. J. Hum. Evol. 63, 300-308.

Stanistreet, I.G., McHenry, L.J., Stollhofen, H., de la Torre, I. (this volumesubmitted) Bed II Sequence Stratigraphic context of EF-HR and HWK EE archaeological sites, and the Oldowan/ Acheulean succession at Olduvai Gorge, Tanzania. J. Hum. Evol.

Stoops, G., 2003. Guidelines for Analysis and Description of Soil and Regolith Thin Sections. Soil Science Society of America, Inc., Madison, Wisconsin.

Stoops, G., Marcelino, V., Mees, F., 2010, Interpretation of Micromorphological Features of Soils and Regoliths. Elsevier, Amsterdam.

Tukey, J., 1949. Comparing individual means in the analysis of variance. Biometrics 5:2, 99114. 
Uno, K.T., Rivals, F., Bibi, F., Pante, M., Njau, J.K., de la Torre, I.(submitted). Large mammal diets and paleoecology across the Oldowan-Acheulean transition at Olduvai Gorge, Tanzania from stable isotope and tooth wear analyses. J. Hum. Evol.

Woodcock, N.H., 1977. Specification of fabric shapes using an eigenvalue method. Geological Society of America Bulletin 88, 1231-1236. 


\section{Figure captions}

Figure 1. Location of Olduvai Gorge with localities mentioned in the text. Map outline and aerial view after Jorayev et al. (2016).

Figure 2. Measured stratigraphic sections for Bed II between KK and HWK W, including the excavation site at HWK EE (see location of sections in Fig. 1). The HWK EE site sits largely within the Lower Augitic Sandstone (LAS), which fills a major incision surface that cuts into Lower Bed II in places, at some sites removing Tuff IIA and the Lemuta member in its entirety. The orange-hued Tuff IIB zone, which includes a variety of different lithologies, but which usually includes tuffaceous siltstone layers, sits above the archaeologically most productive layers at HWK EE. While the widespread marker Bird Print Tuff is not preserved at HWK EE or at any sites to the east, it is found above the Tuff IIB zone at a site $75 \mathrm{~m}$ from HWK EE to the west.

Figure 3. a) Aerial view of HWK EE trenches. b) Digital elevation model (DEM) of the HWK EE outcrop, based on imagery produced by Jorayev et al. (2016). c) Close up of the HWK EE trenches from the air. See SOM S1 for an interactive model and a video clip of the HWK EE locality.

Figure 4. Correlated backwall/sidewall maps of the HWK EE trenches. The lowermost stratigraphy comprises claystones of Lower Bed II, overlain by sandstone layers of the Lemuta Member. All trenches preserve Tuff IIA, a set of tuffaceous sandstones within the Lemuta Member that represents the middle sandstone tongue of the "eolian tuffs" mapped by Hay (1976), identified by their characteristic "salt-and-pepper" texture. In T1- Main Trench and T27, a clayey sandstone fills an incision into the top of that Lemuta sandstone unit. All three satellite trenches preserve a Lemuta claystone above the sandstone unit, but this is not present at T1-Main Trench, because higher portions of the Lemuta Member are then truncated by a disconformity, on top of which lies the LAS of Middle Bed II. T1-Main Trench, which was excavated further back into the hillslope, also exposes sediments above the LAS, including orange-hued sediments (including the sandy clay diamictite), provisionally correlated to the Tuff IIB interval exposed at nearby HWK E. A simplified version of the stratigraphy and the archaeological correlations is presented in Fig. 20. $\mathrm{M}$ a.s.I = meters above sea level.

Figure 5. a) Stratigraphic layers in the backwall (NW-SE) and sidewall (NE-SW) of T1-Main Trench, with locations of phytolith, diatom and sedimentology bulk samples and micromorphology blocks. b)-d) Stratigraphic sections of T29, T28 and T27, with location of bulk samples. e)-f) Sedimentological classification of bulk samples according to Folk's (e) and 
Sheppard's (f) methods. g) Sands versus silts + clays proportions in bulk samples (\#). See raw data in Table 2.

Figure 6. Maps of findings with all archaeological units excavated in T1-Main Trench. a) NESW cross-section. b) NW-SE cross-section. c) 3D view of all materials. d) Composite georeferenced pictures of the back and sidewalls of T1-Main Trench with cross-sections of materials within $50 \mathrm{~cm}$ from the wall. e) Georeferenced aerial view of T1-Main Trench with the horizontal position of materials from all archaeological units. See SOM S2 for 3D rotating view of archaeological units.

Figure 7. a) Clustering of artefacts based on PAM method with optimum number of clusters $(n=4)$; b) Two sections used in statistical operations to establish whether vertical clustering is more pronounced in different areas of the trench; c) Classification of artefacts by their $Z$ (altitude) value, with Jenks' natural breaks method (five classes); d) Material differentiated by archaeological units as defined during fieldwork.

Figure 8. Distribution maps of archaeological unit L10 in T1-Main Trench. a) Plan view (see Figs. 9a and 9b for pictures of selected fossils, and Fig. 22a for a lithic refit set). b) NW-SE cross section of all L10 remains. C) NW-SE cross section of L10 remains within a one-meterwide area between (1) and (2) in the plan view. D) NE-SW cross section of all L10 remains. E) NE-SW cross section of L10 remains within a one-meter-wide area between (3) and (4) in the plan view. Refit line shown in cross-sections correspond to the artefact illustrated in Fig. 22a. See an interactive model of L10 in SOM S3, and video clip in SOM S4.

Figure 9. Fossils unearthed during the excavations of T1-Main Trench. a) Equus oldowayensis mandible from L10. b) Equid femur from L10. c) Concentration of proboscidean and bovid fossils in L4, including a skull of Parmularius aff. rugosus (centre of the image). d) Parmularius angusticornis from L4. e) L4 Kolpochoerus sp. mandible. See Fig. 8 and Fig. 12 for position of fossils from L10 and L4, respectively. Scale bars in cm.

Figure 10. Distribution maps of archaeological unit L6-LCHA in T1-Main Trench. a) Plan view. b) NW-SE cross section of all L6-LCHA material. c) NW-SE cross section of L6-LCHA remains within a one-meter-wide area between (1) and (2) in the plan view. d) NE-SW cross section of all L6-LCHA material. e) N-S cross section of L6-LCHA remains within a one-meter-wide area between (3) and (4) in the plan view (alignment with true North enables positioning of coordinates (UTM36S) in the $x$ - axis). 
Figure 11. Micromorphology photographs of archaeological units L6 and L4 of T1-Main Trench: a) Upper part of L6 (sample \#26B), with poorly preserved fish bone within a layer of mixed clay and fine sands (PPL, frame width= $4.62 \mathrm{~mm}$ ). b) Broad burrow in sample \#26B ( $P P L$, frame width $=\sim 4.62 \mathrm{~mm}$ ). c) Lower part of L6 (sample \#26A), with bone fragments within sands and small amounts of matrix sediment (PPL, frame width $=\sim 2.38 \mathrm{~mm}$ ). d) Clayey inwash in sample \#26A (OIL, frame width $=\sim 4.62 \mathrm{~mm}$ ). e) Example of burrow edge in the top of archaeological unit L4 (sample \#27A) (OIL, frame width= $\sim 4.62 \mathrm{~mm}$ ). f) Leached bone within the sample \#27B sediments (PPL, frame width= $1.5 \mathrm{~mm}$ ).

Figure 12. Distribution maps of archaeological unit L4 in T1-Main Trench. a) Plan view; see Figs. 9c-e for pictures of selected fossils, and Fig. 22b for a lithic refit set. b) NW-SE cross section of all L4 remains. c) NW-SE cross section of archaeological material within a onemeter-wide area between (1) and (2) in the plan view. d) NE-SW cross section of all L4 remains. e) NE-SW cross section of fossils and stone tools within a one-meter-wide area between (3) and (4) in the plan view. Refit line shown in cross-sections correspond to the artefact illustrated in Fig. 22b.

Figure 13. Distribution maps of archaeological unit L2 in T1-Main Trench. a) Plan view; see Fig. 22c for picture of the fossil refit set. b) NW-SE cross section of all L2 remains. c) NW-SE cross section of L2 archaeological material within a one-meter-wide area between (1) and (2) in the plan view. d) NE-SW cross section of all L2 remains. e) NE-SW cross section of archaeological remains within a one-meter-wide area between (3) and (4) in the plan view. Refit line shown in cross-sections corresponds to the fossil photographed in Fig. 22c.

Figure 14. Photomicrographs of L2 (sample \#28 in Figure 5). a) Upper part of archaeological unit L2 (\#28A): gravel-size clay aggregate composed of embedded minerals and Al-Si clay clasts (PPL, frame width= $4.62 \mathrm{~mm}$ ). b) Possible clay inwash in upper L2 (\#28A) (PPL, frame width $=\sim 2.38 \mathrm{~mm}$ ). c) SEM/EDS X-ray backscatter of partially leached bone (cf. fish vertebra); unleached area of bone with $34.1 \% \mathrm{P}_{2} \mathrm{O}_{5}$ and $46.9 \% \mathrm{CaO}$ (Spectrum 1). d) SEM/EDS X-ray backscatter image of clayey aggregate; Spectrum 2 includes 1.11\%P (2.55\% $\mathrm{P}_{2} \mathrm{O}_{5}$ ). e) Thin section of \#28B (lower part of L2), with relict FeMn root traces (arrows) and burrowed area (b) (frame width $=\sim 50 \mathrm{~mm}$ ). f) Probable FeMn stained root trace (root wall = $\sim 750 \mu \mathrm{m})$ and fish bone fragment (PPL, frame width $=\sim 4.62 \mathrm{~mm}$ ). g) Detail of Figure 14f, under OIL (frame width $=\sim 2.38 \mathrm{~mm}$ ).

Figure 15. Distribution maps of archaeological unit L1-L1A in T1-Main Trench. a) Plan view; see Fig. 22d and Fig. 22e for pictures of the lithic refit sets. b) NW-SE cross section of all L1L1A remains. c) NW-SE cross section of L1-L1A archaeological material within a one-meterwide area between (1) and (2) in the plan view. d) NE-SW cross section of all L1-L1A remains. e) NE-SW cross section of L1-L1A archaeological remains within a one-meter-wide 
area between (3) and (4) in the plan view. Lithic refit lines shown in cross-sections correspond to artefacts from Fig. 22d and Fig. 22e.

Figure 16. Thin section photographs of L1 sediments (sample \#29 in Fig. 5). a) Scan of sample \#29B (upper part of L1), showing broadly layered massive sands and fine gravel with two calcium carbonate layers (red and blue arrows) (frame width $=\sim 50 \mathrm{~mm}$ ). b) Upper layer shown in Fig. 16a, with dark (potentially FeMn staining) surface weathering on carbonatecemented sand substrate (cf. algae/cyanobacteria), below calcium carbonate cemented clayey soil clasts (PPL, frame width $=\sim 4.62 \mathrm{~mm}$ ). c) Lower layer shown in Fig. 16a, composed of clay laminae, sparitic calcite laminae and cementation of sand-size clasts. There has also been (brown) clayey inwash (PPL, frame height= $4.62 \mathrm{~mm}$ ). d) Scan of sample \#29A (lower part of L1), with massive sediment with dark burrow (b) fills. Later root trace is arrowed (see detail in Figs. 16e-16f) (frame width $=\sim 50 \mathrm{~mm}$ ). e) Root trace arrowed in Fig. 16d, probably Fe-Mn replaced (PPL, frame width $=\sim 4.62 \mathrm{~mm}$ ). f) XPL version of Fig.16e, showing how rooting has decalcified the calcium carbonate in $\mathrm{L} 1$.

Figure 17. a) Georeferenced photo merge of T27 stratigraphy with vertical plotting of archaeological units (remains within $1 \mathrm{~m}$ from the backwall). b-e) Plan views of most relevant archaeological units in T27.

Figure 18. a) NW-SE stratigraphy of T28 with vertical distribution of archaeological units (remains plotted within $1 \mathrm{~m}$ from the backwall). b) Plan view of archaeological unit T28L40. c) Plan view of T28L41. d) Detail of T28L41 remains (see location at the top left corner of Fig. 18c). e-h) Distribution maps of the bottom of LAS (e) and the Lemuta archaeological units (fh).

Figure 19. a) Georeferenced photo of T29 stratigraphy with vertical plotting of archaeological units (remains within $1 \mathrm{~m}$ from the backwall). b-d) Maps of T29 archaeological units.

Figure 20. a) Block diagram of stratigraphic and archaeological correlations of HWK EE trenches. Thickness of stratigraphic layers and elevation of archaeological units are averaged from ArcGIS cross-sections. b) NW-SE cross section of all archaeological remains according to the three main stratigraphic intervals (Tuff IIB, Lower Augitic Sandstone and Lemuta). c) Summary of correlation of archaeological units within each stratigraphic interval. d) NW-SE cross section of archaeological units with breaks in the horizontal distance (see Fig. 20b for true distances). 
Figure 21. Refits between trenches (a-e) and between T1-Main Trench archaeological units (f-h). a-b) Plan view of the refit between T1-Main Trench and T28, aligned with true North (a) and the HWK EE grid (b). c-d) NW-SE cross-sections of T1-Main Trench archaeological unit L1 and T28L40, with true distance (d) and breaks in the $\mathrm{x}$-axis (c). e) Split cobble refit between T1-Main Trench and T28. Scale: $3 \mathrm{~cm} \mathrm{f)} \mathrm{Posterior} \mathrm{view} \mathrm{of} \mathrm{the} \mathrm{inter-level} \mathrm{refit} \mathrm{of} \mathrm{a}$ Parmularius angusticornis (cf. Bibi et al., submitted) skull between L4 (horn cores) and L1 (occipital). Scale: $10 \mathrm{~cm}$ g-h) NW-SE cross section (g) and plan view (h) of the L1-L4 bone refit.

Figure 22. Examples of refit sets in T1- Main Trench (a-e) and T29 (f) at HWK EE. a) Fractured flake from L10; location is marked in maps from Figure 8 . b) Core and flake refit from L4 (see Fig. 12 for location). c) Bovid metatarsal from L2: see location in Fig. 13. d-e) Fractured flake (d) and core-flake (e) conjoin sets from L1; locations are marked in Fig. 15. f) Fractured flake from T29L50. All scales in cm.

Figure 23. a-b) Density of archaeological remains in each archaeological unit by area $\left(\mathrm{m}^{2}\right)$ and estimated volume $\left(\mathrm{m}^{3}\right)$. c-d) Overall density of fossils and stone tools per trench. e-f) Density of archaeological remains in each stratigraphic interval per trench. g-h) Density of archaeological remains per lithofacies. i-j) Overall density of archaeological remains in stratigraphic intervals preserved in the HWK EE trenches. All data from Table 4. See calculations in SOM S6.

Figure 24. Microphotographs of representative diatoms identified in sample \#84. Pseudostaurosira brevistriata (1), Staurosirella pinnata (2), Staurosira sp. (3), Planothidium cf. frequentissimum (4), Cocconeis sp. (5), Cocconeis cf. placentula (5-7), Navicula spp. (810), Gomphonema cf. parvulum (11-13), Gomphonema sp. (14-16), Amphora sp. (17), Placoneis sp. (18), Anomoeoneis sp. (19), Diploneis sp. (20), Nitzschia species 1 (21), Nitzschia cf. epiphytica (22), Nitzschia amphibia (23-28), Nitzschia species 2 (29-30).

Figure 25. a) HWK EE histogram showing percentage of phytoliths from each plant category / part, grouped by sample (\#). b-v) Microphotographs of phytoliths from HWK EE trenches (images taken at 400x). b) Elongate phytolith from sample \#48 (T27) presenting signs of chemical dissolution. c-d) Multicellular structures from samples \#81 and \#87 (both from T1Main Trench). e-f) Spheroid echinate from sample \#66 (T28), and from sample \#81 (T1-Main Trench). g) Trichome from sample \#81 (T1-Main Trench). H-J) Bulliform cells from samples \#66 (T28) and \#81 (T1-Main Trench). k-I) saddles from samples \#66 (T28) and \#81 (T1-Main Trench). m-o) Rondels from samples \#93 (T29), \#81 and \#87 (both at T1-Main Trench). p) Bilobate from sample \#93 (T29). q) Sedge phytolith from sample \#66 (T28). r) Blocky from sample \#84 (T1-Main Trench). s) Hair base from sample \#84 (T1-Main Trench). t) Platelet 
from sample \#66 (T28). u) Platelet pitted from sample \#66 (T28). v) Irregular from sample \#22 (T1-Main Trench). See Fig. 5 for location of samples.

Figure 26: Unmodified lithics in HWK EE: a) Plan view of unmodified material in relevant archaeological units of T1-Main Trench. b) Length and width distribution of unmodified lithics in the entire HWK EE sample. c) Clusters of unmodified cobbles during the excavation of L6. Arrow points to geographic North.

Figure 27. Density maps of unmodified material in relevant archaeological units ( $a$ and $b$ ) and intervals (c) at T1-Main Trench. a) Unmodified pebbles. b) Unmodified cobbles. c) Unmodified lithics (including pebbles and cobbles) compared to archaeological items (i.e. fossils and stone tools) in LAS and Lemuta. See SOM S6 for sample sizes and results of Clark and Evans test.

Figure 28. Comparisons between natural (cobbles and pebbles) and modified (battered/ flaked and detached) materials in HWK EE. a) Absolute frequencies in each archaeological unit. b) Correspondence factor analysis (CFA) of materials per archaeological unit. c) Absolute frequencies per stratigraphic member in each trench. d) Adjusted residuals of trench/ stratigraphic member. e) CFA of trench/ stratigraphic member. f) Absolute frequencies per litho-stratigraphic unit. g) Adjusted residuals of litho-stratigraphic units. $h$ ) CFA of litho-stratigraphic units. i) Absolute frequencies in each stratigraphic member. j) Adjusted residuals per stratigraphic member. k) Absolute frequencies of archaeological versus natural lithics per stratigraphic member. I) Adjusted residuals of archaeological versus natural lithics per stratigraphic member. $m$ ) Frequencies of observed and expected stone tools in the Chi-squared test, per each of the five Jenks' natural breaks classes of all lithics. n) Frequencies of observed and expected unmodified lithics in the Chi-squared test, per each of the five Jenks' natural breaks classes of all lithics. o) Comparison of frequencies of unmodified lithics in LAS and Lemuta intervals, by means of the observed and expected numbers in Chi-squared tests for six $20 \mathrm{~mm}$ length classes. p) Proportions of observed and expected stone tools, and observed unmodified lithics, in Sneed and Folk's shape classes (based on the Chi-squared test of significance). All data from Table 3.

Figure 29. Covariation of fossil and lithic remains (natural and modified) in HWK EE. a) Absolute frequencies in each archaeological unit. b) CFA per archaeological unit. c) Absolute frequencies per stratigraphic member in each trench. d) Adjusted residuals per stratigraphic member. All datasets include fossils and lithics $>20 \mathrm{~mm}$ only ( $n=4,846$ bones, 5,171 stone tools and 1,928 unmodified lithics). 
Figure 30. Edge roundness in the HWK EE stone tool assemblage. a) Entire assemblage. b) Trench. c) Stratigraphic interval. d) Lithofacies. e) Raw material. f) Size groups. g) Weight groups. h) Flaked/battered versus debitage. All data from Table 15.

Figure 31. Dimensional features of the HWK EE stone tool assemblage. a) Relative frequency of weight classes. b) Relative frequency of $20 \mathrm{~mm}$-interval length classes. c) Cumulative frequency of length and width in the entire stone tool assemblage. d) Adjusted residues of Chi-squared comparison between Lemuta and LAS length classes. e-g) Empirical Cumulative Distribution Functions (ECDF) of raw material (e), Lithology/ interval ( $f$ ) and interval (g) length distributions; significantly divergent datasets are shown in black. D statistic in Kolmogorov-Smirnov test is the further distance between ECDF of two samples (see also SOM S8 and S9). h) Cumulative frequency of length and width in artefacts $<20 \mathrm{~mm}$. i-j) Size ranges within the $<20 \mathrm{~mm}$ length class per stratigraphic interval (i) and lithofacies (j).

Figure 32. Length histograms of all stone tools (a) and stone tools $<20 \mathrm{~mm}$ (b), according to raw material (top left), lithofacies (top right), litho-stratigraphic unit (bottom left) and stratigraphic interval (bottom right).

Figure 33. Orientation patterns of all measured items (blue) and those with le> 1.6 (black). a) Mean vectors. b) Circular histograms per archaeological unit. c) Circular histograms per trench, stratigraphic interval and lithofacies.

Figure 34. Circular histograms per litho-stratigraphic unit (a) and per interval (b), with all measured items (blue) and those with le> 1.6 (black).

Figure 35. Aerial view of the area around T28, T27 and T1-Main Trench, with orientation patterns per sector. a) Orientations and main modes of all measured items in T28, T27, and $2 \times 2 \mathrm{~m}$ sectors along the T1- Main Trench grid. $\mathrm{b}-\mathrm{c}$ ) Orientations and primary and secondary modes for LAS (b) and Lemuta (c) materials in T28, T27 and two areas of T1 (each combining five of the sectors in Fig. 35a). See Table 16 for bearings of primary and secondary modes of each rose diagram.

Figure 36. Benn's diagrams (fabrics) of all items (right) and objects with le> 1.6 (left). a) relevant archaeological units. b) Fabrics per trench, stratigraphic interval and lithofacies. c) Fabrics per litho-stratigraphic unit. d) Fabrics per interval. 
Figure 37. Density maps of T1-Main Trench materials per archaeological unit. a) All items (fossils, stone tools and unmodified lithics). b) Fossils. c) Stone tools. Spatial distribution of items according to length, weathering and raw material is available in SOM S18-S22.

Figure 38. Density maps of T1-Main Trench materials. a) Distribution of flaked/ battered stone tools per archaeological unit. b) Debitage distribution per archaeological unit. c) Kernel density maps comparing LAS (top) and Lemuta (bottom) intervals for all objects, lithics (unmodified and stone tools), and fossils.

Figure 39. a) Kernel density estimates for LAS (A1) and Lemuta (A2) intervals. Point patterns (see SOM S29) and densities (SOM S28) are estimated for both eroded and uneroded areas, under presumption of continuity of surface in each interval. b) Probability surfaces for material location in Tuff IIB (B1), LAS (B2) and Lemuta (B3) intervals, based on artefact density and modern terrain features. 